\title{
Problem-solving training modifies cognitive functioning and related functional connectivity in healthy adults
}

Béatrice Alescio-Lautier ${ }^{\mathrm{a} * 1}$, Caroline Chambon ${ }^{\mathrm{a} 1}$, Claire Deshayes ${ }^{\mathrm{a}}$, Jean-Luc Anton ${ }^{\mathrm{b}}$, Guy Escoffier ${ }^{c}$ Marie-Hélène Ferrer ${ }^{d}$, Véronique Paban ${ }^{a}$

a Aix Marseille Univ, CNRS, LNC-UMR 7291, NeuroMarseille, InCiam, 3 Place Victor Hugo, 13331 Marseille Cedex 03, France

b Aix Marseille Univ, CNRS, Centre IRM-INT@CERIMED, Institut de Neurosciences de la Timone ; UMR7289 CNRS \& AMU ; Faculté de Médecine de la Timone ; 27 Bd Jean Moulin ; 13005 Marseille

c Aix Marseille Univ, CNRS, INP, UMR 7051, Faculté de pharmacie, campus Timone, 27 bvd Jean-Moulin 13385 Marseille, France

d Département Neurosciences et Contraintes Opérationnelles (NCO), Institut de Recherche Biomédicale des Armées (IRBA) 91223 Brétigny-sur-Orge, Cedex, France

\section{*Corresponding author at:}

Laboratoire de Neurosciences Cognitives - UMR 7291, Aix Marseille Univ \& Centre National de la Recherche Scientifique (CNRS), Centre Saint-Charles- Case B, 3, Place Victor Hugo, 13331 Marseille Cedex 03, France Tel: +33 (0) 413550883.

E-mail: Beatrice.alescio-lautier@univ-amu.fr

${ }^{1}$ Béatrice Alescio-Lautier and Caroline Chambon contributed equally to the present study

\section{Abbreviations:}

AVE: Average Variance Extracted, PLS-SEM: Partial least squares variance-based structural equation modeling, ICA: independent component analysis, FDR: false discovery rate, ICs: independent components. 


\begin{abstract}
Cognitive functioning evolves throughout life. Regular practice of stimulating activities maintains or even strengthens cognitive skills. This study investigated the effects of a cognitive training program based on complex closed-ended problem solving on innovative thinking. To this end, using partial least squares variance-based structural equation modeling, we first evaluated in 83 healthy adults how inhibition, cognitive flexibility, and reasoning were related to the distinct dimensions of innovative thinking. Second, we assessed how these interactions were modified after cognitive training based on problem solving in a subgroup of 16 subjects compared to leisure activity based on crossword solving in another subgroup of 15 subjects. Third, in a pilot fMRI study, we evaluated changes in brain connectivity at rest as a result of training in the problem solving group. Data on cognitive measures showed that innovative thinking was influenced by reasoning in control subjects, whereas it was influenced by cognitive flexibility following problem-solving training. These findings highlight that a cognitive intervention based on complex closed-ended problem solving promotes innovative thinking by changing the way subjects recruit and use relevant cognitive processes. Modifications in the restingstate connectivity of attention, default mode and visual networks were observed in the problem solving group.
\end{abstract}

\title{
Keywords
}

Problem-solving training, Flexibility, Innovative thinking, Resting state, Graph theory

\section{Introduction}

Cognitive functioning evolves throughout life. The regular practice of stimulating activities is thought to maintain, or even reinforce, cognitive abilities. Studies have shown longterm effects in participants after cognitive training (Schaie, 1996, 2004); however, different cognitive and personality profiles coexist. These individual differences must be considered during cognitive training to use specific skills to promote improvements. (Schaie, 1994). Hence, stimulating activities must be customized to each subject's skills to be effective. Many studies have assessed the extent to which cognitive training can increase or restore functions, as well as propel an individual beyond its norms.

\subsection{Cognitive training}

Many studies report improved cognitive functioning in healthy older adults or slower declines in individuals with mild cognitive impairment after cognitive interventions (Lustig et al., 2009; Gates and Valenzuela, 2010; Kurtz et al., 2011). Stigsdotter \&
Bäckman (1989) and Stigsdotter-Neely \& Bäckman (1993) proposed a program that included training in several types of mnemonic procedures. This program improved the memory performance of elderly subjects in various episodic memory tasks for six months. The ACTIVE (Advanced Cognitive Training for Independent and Vital Elderly) study, the largest to date, involved 2802 elderly Americans and compared 3 training programs, one based on mnemonic strategies, another on reasoning and the last on processing speed (Ball et al., 2002). The results indicated that subjects improved on the tasks specifically targeted by each of the three interventions. Interestingly, the benefits of training programs focused on information processing speed generalize to daily life (Roenker et al., 2003; Edwards et al., 2005; Ball et al., 2007) and quality of life (Wolinsky et al., 2006). Other interventions based on multifactorial approaches have shown encouraging results (Stigsdotter-Neely \& Bäckman, 1995; Yesavage \& Rose, 1983; Yesavage et al., 1990). Belleville et al. (2006) reported improved performance on untrained memory tasks in elderly subjects undergoing 
multifactorial memory training. Winocur et al. (2007) and Levine et al. (2007) reported that following multifactorial memory training that included goal management and psychosocial skills in addition to memory training, older adults were able to transfer the benefits of training to other cognitive tasks such as language. Hussey and Novick (2012) also stipulated that the training of executive functions induces a benefit for language processes. In previous studies, we reported that a multifactorial cognitive training program targeting consciously controlled processes at encoding had a positive effect on cognition in healthy older adults (Chambon et al., 2014; Chambon and Alescio-Lautier, 2019), in individuals with mild cognitive impairment (Herrera et al., 2012) and in individuals with early-stage Alzheimer's disease (AlescioLautier et al., 2019). Thus, many studies confirm the efficiency of cognitive training in improving several cognitive functions as well as, in helping the transfer of benefits to untrained functions. However, in most cases, this transfer takes place under conditions similar to the training, whereas it is also important that this transfer can occur in conditions very different from those during the training, such as those encountered in daily life, so that the individual can adapt more easily to their environment. In this context, interventions should be explored that could influence the individual's way of thinking, character traits, etc., in order to make them more adaptive.

\subsection{Creativity and problem solving}

New cognitive interventions to help people with the demands of daily life remain unexplored. To help people cope with the difficulties of everyday life, it is necessary to find alternative interventions. In this sense, creativity could be a key ability by providing individuals with additional resources to solve complex and novel situations. Therefore, in addition to training proposed to improve cognitive functioning, those that stimulate creativity have grown in number and are of great interest (Vally et al., 2019; Meinel et al., 2018; Puccio et al, 2020). Since creativity has many facets, creativity training can be based on a variety of approaches (Scott et al., 2004). Among them, idea generation training is undoubtedly the most commonly used approach (Clapham, 1997; Baruah and Paulus, 2008). However, other approaches, such as training creative processes, conceptual combination and critical thinking, have also been used and are equally effective (Murdock et al, 1993, Puccio et al., 2020).

Numerous studies have highlighted the importance of executive engagement and cognitive control during creative thinking as assessed by divergent thought tasks (Benedek et al., 2014). In this study, we wanted to situate our intervention ahead of creative thinking, i.e., by acting on executive processes that will generate creative thinking. In a previous study (Deshayes et al., 2021), we showed that subjects with high creative potential show a positive correlation between working memory and creativity that we do not find in subjects with low creative potential. We believe that a focus on executive mechanisms that support creative thinking, some of them being involved in working memory, and on executive strategies could promote creative thinking use in a variety of contexts. To achieve this goal, we proposed a cognitive intervention based on problem solving that could foster the ability to depart from the usual constraints and promote cognitive attributes, such as nonjudgment, willingness, and plasticity that enable one to think differently and engage more fully in everyday life. Nonjudgment is an important attribute in the sense that it is preferable not to have any initial preconceived notions when solving a problem. Preconceived ideas are often limiting because they prevent frame breaking that generally leads to a solution. We can then think that if we are nonjudgmental and therefore without preconceived ideas about a problem, it makes it easier to solve and that an intervention based on problem solving promotes nonjudgment which will facilitate resolution (Ness, 2012; 2015; McCarthy, 2018). Willingness will also be promoted because problem solving is a challenging field that easily leads to failure. Problem solving requires much effort, and it often challenges the individual's abilities. It is therefore necessary to 
have the willingness to keep on training. In addition, this type of cognitive intervention could be successful in creating a conscious relationship between cognitive improvements and the ability to make everyday life problems easier to solve, which may ultimately change the recruitment and use of relevant cognitive processes to cope with demands. We believe that as the individual progresses through the training process, he or she acquires skills and solves problems more easily, which leads to adaption to new situations. The awareness of this new expertise could lead the individual to1.3.Brain changes related to cognitive training think differently about his daily problems and to be more resilient.

Conventionally, a problem arises if we have a goal but do not know how to reach it. Hence, solving problems implies procedures that are generally still unknown (Wimmer, 2016). Frame-breaking, i.e., to get out of one's usual way of thinking, is often required to find novel solutions. Indeed, individuals often do not find solutions because frame breaking involves the implementation of a series of innovative heuristics and tools (Ness, 2015). Moreover, divergent and convergent thinking are both involved in effective novelty (Guilford, 1967). Specifically, divergent thinking involves new idea generation, a variety of approaches, and the ability to transform information to create new prospects and turn challenges into opportunities. Convergent thinking involves evaluating novelty and looking for accurate stored information, which enables one to choose the best answer (Cropley, 2006). In particular, during problem solving, convergent thinking makes it possible to explore, evaluate, or criticize the variability generated by divergent thinking and identify its effective aspects. This interplay between divergent and convergent thinking during problem solving fosters the flexible engagement of numerous cognitive processes, such as the focus and defocus of attention and inhibition, respectively. Thus, flexibility, whether attentional or applied to different processes, seems to be essential. Regarding inhibition, studies have shown that inhibitory control supports creativity (Stavridou and Furnham, 1996; Takeuchi et al., 2011; Radel et al., 2015; Cassoti et al., 2016). Thus, we believe that problem-solving training using appropriate instructions and specific problems that promote frame breaking and alternatively involve convergent and divergent thinking should improve the ability of individuals to solve problems by improving innovative thinking. The work of Tik et al. (2018) showing that the remote associates test that requires both divergent and convergent thinking to provide insightful solutions supports our assumption.

According to a systematic review of clinical trials with healthy older adults by Valenzuela and Sachdev (2009), training stimulates neuroprotective mechanisms that limit neuronal dysfunction and thus maintain cellular integrity. Cognitive training would lead to the activation of brain areas that would promote functional reorganization, thus strengthening the functionality of neuronal networks. Many studies support this hypothesis. (Valenzuela et al. 2003; 2008) show that cognitive training in elderly individuals increases the level of neuroprotective metabolites in the hippocampus and that the level of mental activity is inversely related to the rate of hippocampal atrophy in healthy elderly individuals. Increased brain metabolism in the frontal lobe was also reported after cognitive training by Small et al. (2006) and Raz and Buhle (2006), who showed a strengthening of the neural networks of control processes following attentional training. Chapman et al. (2017) evaluated the effect of cognitive reasoning training on innovative cognition in healthy adults. They reported increased cerebral blood flow in the medial orbitofrontal cortex and bilateral posterior cingulate cortex following training. Many programs target working memory and demonstrate the facilitation of cognitive functioning. Indeed, Westerberg et al. (2007) found significantly increased activation in the middle or inferior frontal gyrus and parietal cortex following working memory training. Some research observed both increased and decreased brain activation after training. This is the case of 
Dahlin et al., who reported in younger adults increased activation in the left striatum but also decreased activity in frontal and parietal areas after working memory training (2008). However, Miro-Padilla et al. (2019) showed that increased performance after working memory training was associated with decreased activation in the frontal superior/middle cortex, inferior parietal cortex, anterior cingulate cortex, and middle temporal cortex. These authors interpreted the reduction in activations after training as a better neural efficiency in that the positive effects of training reduced the required task demands.

Some studies reported training-related brainstate changes at rest, indicating greater connectivity in the default mode network (DMN) and the central executive network (Chapman et al., 2015; 2017; Cao et al., 2016), and interestingly, the increase in subjects' creative performance after repeated exposure to creative tasks is accompanied by changes in resting state connectivity. Indeed, Fink et al. (2018) reported modulation of functional connectivity in the DMN, the sensorimotor network (SMN), the auditory network (AUN), and the attention network (AN).

In light of all of these data, we investigated the effects of a cognitive training program based on problem solving on innovative thinking. Our underlying assumption was that problem-solving training would improve innovative thinking by changing the way executive processes, such as inhibition, attentional flexibility, and reasoning are involved. To evaluate this assumption, in the first study, we used a sample of cognitively typical adults to identify how inhibition, cognitive flexibility, and reasoning were related to the distinct dimensions of innovative thinking. In a second study, we assessed how these interactions were modified after cognitive training based on problem solving, and in a third fMRI pilot study, we investigated whether this training could induce changes in brain functional connectivity at rest. Based on the above data, we believe that the study of brain connectivity at rest is relevant to highlight changes in functional connectivity after cognitive training and hope that our study will contribute to improving this field of research.

\section{Experiment 1: Innovative thinking and executive mechanisms}

\subsection{Materials and methods}

\subsubsection{Participants}

We recruited 83 healthy subjects between 20 and 40 years of age (age means \pm $\mathrm{SD}=26.51 \pm 2.73$ years, $\mathrm{M} / \mathrm{F}=36 / 47)$. Participants were students and staff at AixMarseille University who were recruited through advertisements and received monetary compensation for their participation in the study. They had no history of neurological or psychiatric illness. All the participants provided written, informed consent in accordance with procedures approved by the local ethics committee, which followed the recommendations of the Declaration of Helsinki.

\subsubsection{Cognitive tasks}

According to our hypothesis, problemsolving training would improve innovative thinking by changing the way executive processes, such as inhibition, cognitive flexibility, and reasoning, are involved.

Hence, to assess inhibition, we administered the Stroop test (Golden, 1978), which is a classic measure of cognitive inhibition. The time (in seconds) required to complete each test was used for cognitive analyses.

To assess cognitive flexibility, we administered an attention task that was developed in our laboratory and described previously (Herrera et al., 2012; Chambon et al., 2014; 2019). First, the participant has to remember a target picture presented in the center of the screen. Then, two pictures $(50 \%$ target, 50\% lures) appeared at the same time on the left and right sides of the screen. The task includes 4 variants, but in this study, participants performed variants 3 and 4 . In Variant 3 and for the first trial, one of the two pictures was pointed to by a green arrow. The 
participants had to respond if the picture pointed to by the arrow was the target picture or not by pressing a key "enter" to answer "yes, it is the target," and on the key "esc" to answer "no, it is not the target. They were instructed to ignore pictures that were not pointed to by the arrow even if they were the target picture and to respond as fast and as accurately as possible. Starting the second trial, the arrow appeared only to indicate a change of side. Thus, when the green arrow disappeared, the participant must remember the side where the arrow was last to know and to continue to answer on the same side of the screen until a new arrow appeared. This variant is based on focalized attention, flexibility and short-term memory. In variant 4 , the first time again the green arrow shows the side of interest. However, afterward, a red star appears and shows the side where the participant has to pay attention to the next two following images. In addition to the above mechanisms, this variant is based on shared attention. Each variant included 80 trials. We determined the percentage of correct responses and mean response time (seconds) (see supplemental material).

To assess reasoning, we administered a computerized modified version of the Wisconsin Card Sorting Test according to the Wisconsin Card Sorting Test manual (Heaton et al., 1993). This test assesses reasoning abilities, which involve cognitive flexibility or setshifting, and cognitive strategy modification abilities. This test was scored, in percentages, by the total number of correct answers, erroneous answers, perseverative errors, and nonperseverative errors. We also used a computerized modified version of the Tower of London test. In this computerized version, all displacements must be imagined before an answer is given. In other words, the subjects answered by providing the minimum number of displacements required to reach the target configuration and did not execute the task physically, as is the case in the manual version. The test consisted of the following steps. The participants observed two configurations of three stacked, colored balls (blue, red, and yellow) placed in three holes; the top configuration represented the starting configuration, and the bottom configuration represented the target configuration. From left to right, the first hole could only receive one ball, the second could receive two balls, and the third could receive three balls. The participant was asked to choose between 1 and 5 movements to find the minimum number of displacements required to move from the starting configuration to the target configuration by clicking with a computer mouse on one of the numbers proposed on the screen. The rules of displacement were as follows: 1) one single ball could be moved at a time; 2 ) the moved ball must be on top of the stack; and 3) the moved ball could only be placed in an empty hole or on other balls. The subject performed 10 trials per number of movements, for a total of 50 trials, without a time limit. The Tower of London test is based on reasoning abilities that involve planning, shifting and visuospatial working memory. This test was scored by the correct responses and the time (in $\mathrm{msec}$ ) taken to complete each trial.

To assess innovative thinking, we used the Revised Minnesota Paper Form Board Test (Likert and Quasha, 1941), which Muchinsky (2004) reports involves "imagery capacity, spatial observation, mental visualization skills, art and relational skills, and the ability for an individual to visualize and manipulate objects in space". We were interested in the number of correct responses, to which we subtracted $1 / 5^{\text {th }}$ from the number of wrong answers. Finally, the subjects were asked to solve four insights (Appendix A of Schooler et al., 1993; problem numbers 1, 3, 4, and 7) and four noninsight problems (Appendix B of Schooler et al., 1993; problem numbers 1,2,3, and 4). The dependent measure was the total number of problems (in percent) resolved correctly within the 4-minute time period allotted for each subject. To resolve the problems in a timely manner, subjects were required to use abilities such as willingness to challenge convention. Resolving noninsight problems required the use of conventional research strategies involving logic, recognition and decision making, while resolving insight problems required a prelinguistic form of 
intuitive cognition (the nonverbal and nonlogical basis for imaginative tools).

\subsubsection{Data analysis}

Partial least squares structural equation modeling (PLS-SEM) was used to analyze the cognitive measures. PLS-SEM is an advanced statistical method based on exploratory techniques (Bollen and Lennox, 1991) that performs adequately with small sample sizes (Hair et al., 2014). PLS-SEM first analyzes the measurement model elaborated from indicator variables and then examines the structural model created from latent variables (or constructs). The relationships between constructs are represented by a diagram, in which circles represent constructs and arrows represent relationships. The path model is translated into a set of equations describing a measurement model and a structural model (Haenlein and Kaplan, 2004). The validity of the measurement model was assessed by internal consistency, convergent validity and discriminant validity. Internal consistency was calculated using the composite reliability of the items. The average variance extracted (AVE) scores for each construct and the outer loading of each indicator were examined and represented the convergent validity.
Discriminant validity was evaluated by assessing the cross loading. Regarding the structural model, the quality of the relationships was measured by the $\mathrm{R}^{2}$ metric, which reflects the level of the explained variance of the composites. The effect size $\mathrm{f}^{2}$ was computed (Riou et al., 2016). Statistical comparisons of path coefficients were performed using XLSTAT software, which offers multigroup comparison methods in the framework of PLS path modeling presented by Goles and Chin (2005). An adapted t-test based on bootstrapped standard errors was used. Statistical significance was set at $\mathrm{p} \leq 0.05$.

\subsection{Results}

The measurement model was constructed from data that included all the participants $(\mathrm{N}=83)$ and four reflective constructs: inhibition, reasoning, cognitive flexibility, and innovative thinking. The reliability and validity results are shown in Table 1. The internal consistency measures, as indexed by the composite reliability, ranged from 0.78 to 0.95 , exceeding the recommended threshold value of 0.70 . The convergent validity was acceptable, as AVE was above 0.5 for all four constructs. Each item's factor loading was significant ( $\mathrm{p}<0.05$, data not shown), and all but two were above 0.6 . 


\begin{tabular}{|c|c|c|c|c|c|c|c|}
\hline \multirow[b]{2}{*}{ Constructs } & $\begin{array}{l}\text { Composite } \\
\text { reliability }\end{array}$ & \multirow[b]{2}{*}{ Indicators } & \multicolumn{4}{|c|}{ Outer loadings and cross loadings } & \multirow[t]{2}{*}{ AVE } \\
\hline & & & Inhibition & $\begin{array}{l}\text { Cognitive } \\
\text { flexibility }\end{array}$ & Reasoning & $\begin{array}{l}\text { Innovative } \\
\text { thinking }\end{array}$ & \\
\hline \multirow[t]{5}{*}{ Inhibition } & 0.904 & & & & & & 0.751 \\
\hline & & $\begin{array}{r}\text { Stroop, Color } \\
\text { naming }\end{array}$ & 0.930 & 0.044 & 0.392 & -0.303 & \\
\hline & & Stroop, Color name & & & & & \\
\hline & & reading & 0.760 & 0.042 & 0.172 & -0.132 & \\
\hline & & Stroop, Interference & 0.899 & 0.031 & 0.274 & -0.281 & \\
\hline \multirow[t]{7}{*}{ Reasoning } & 0.855 & & & & & & 0.551 \\
\hline & & $\begin{array}{r}\text { Wisconsin, number } \\
\text { of erroneous }\end{array}$ & & & & & \\
\hline & & answers & 0.261 & 0.094 & 0.904 & -0.442 & \\
\hline & & $\begin{array}{l}\text { Wisconsin, } \\
\text { perseverative errors }\end{array}$ & 0.290 & 0.127 & 0.725 & -0.307 & \\
\hline & & $\begin{array}{l}\text { Wisconsin, non- } \\
\text { perseverative errors }\end{array}$ & 0.233 & 0.075 & 0.893 & -0.419 & \\
\hline & & $\begin{array}{l}\text { Tower of London } \\
\text { test, } 3 \text { moves, time } \\
\text { Tower of London }\end{array}$ & 0.287 & 0.208 & 0.591 & -0.352 & \\
\hline & & test, 4 moves, time & 0.243 & 0.207 & 0.516 & -0.167 & \\
\hline \multirow[t]{3}{*}{$\begin{array}{l}\text { Cognitive } \\
\text { flexibility }\end{array}$} & 0.947 & & & & & & \\
\hline & & $\begin{array}{r}\text { Visuospatial } \\
\text { focused attention } \\
\text { test, Variant 3, time }\end{array}$ & 0.045 & 0.941 & 0.119 & -0.233 & 0.899 \\
\hline & & $\begin{array}{r}\text { Visuospatial } \\
\text { focused attention } \\
\text { test, Variant 4, time }\end{array}$ & 0.038 & 0.954 & 0.199 & -0.263 & \\
\hline \multirow[t]{4}{*}{$\begin{array}{l}\text { Innovative } \\
\text { thinking }\end{array}$} & 0.785 & & & & & & 0.546 \\
\hline & & Minnesota test & -0.404 & -0.081 & -0.303 & 0.690 & \\
\hline & & Insight problems & -0.128 & -0.159 & -0.292 & 0.690 & \\
\hline & & $\begin{array}{r}\text { Noninsight } \\
\text { problems }\end{array}$ & -0.140 & -0.309 & -0.441 & 0.828 & \\
\hline
\end{tabular}

Table 1. Assessment of the measurement model: internal consistency (composite reliability), convergent validity (loading and average variance extracted (AVE)), and discriminant validity (cross loading) 
As the validity of the measurement model was assured, we proceeded to assess the results of the structural model. The results showed that the model was statistically significant, $F=9.89, p=0.0003$, with an $R^{2}$ value of 0.38 , indicating that a substantial amount of the variance was explained. All the paths showed positive correlations, but only the relationship between reasoning and innovative thinking was significant $(\beta=0.546 ; \mathrm{p}<0.001)$ (Fig. 1).

The effect size of each path, calculated through $\mathrm{f}^{2}$ values, confirmed these data, showing a strong effect of reasoning on innovative thinking $\left(\mathrm{f}^{2}=0.40\right)$ and a weak effect of the other 2 paths $\left(\mathrm{f}^{2} \leq 0.04\right)$ (Table 2$)$.

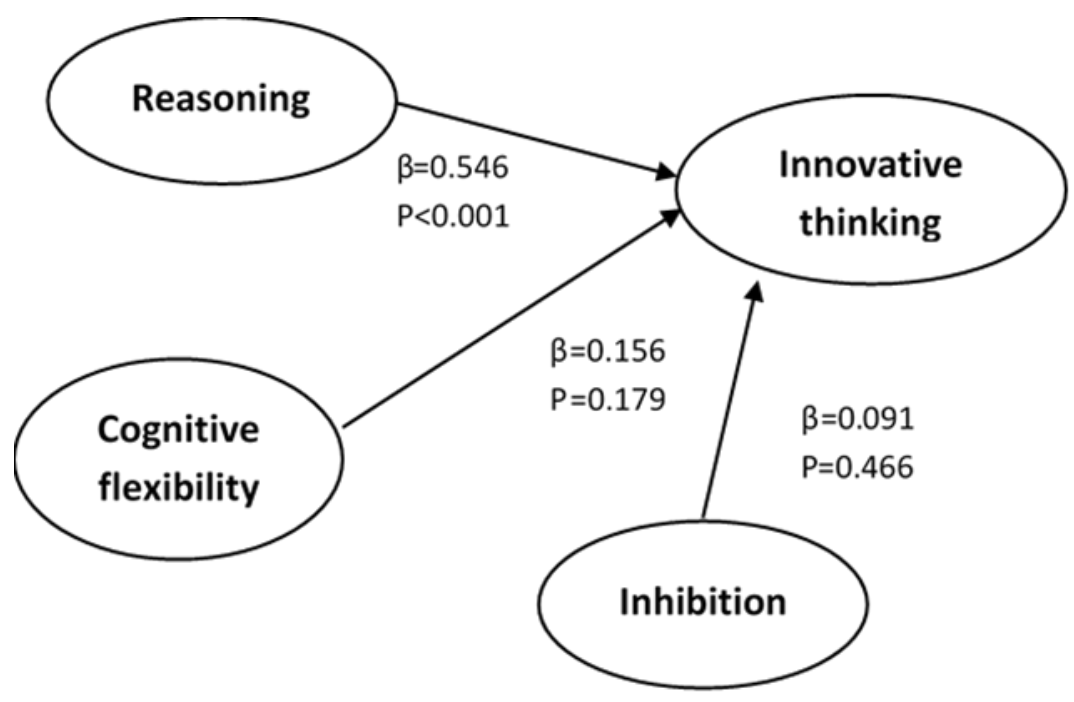

Figure 1: Structural model of the direct effects of reasoning, cognitive flexibility, and inhibition on innovative thinking in 83 healthy subjects.

\begin{tabular}{l|c|c} 
Paths & $\mathbf{f 2}$ & Magnitude of the effect \\
\hline $\begin{array}{r}\text { Model of healthy subjects' group } \\
\text { Reasoning on Innovative thinking }\end{array}$ & 0.40 & High \\
Cognitive flexibility on Innovative thinking & 0.04 & Low \\
Inhibition on Innovative thinking & 0.01 & Low
\end{tabular}

Table 2. Effects sizes of the structural model paths.

\section{Experiment 2: problem solving training}

To evaluate to what extent problemsolving training would improve innovative thinking by changing the weights of each latent variable, i.e., inhibition, cognitive flexibility, and reasoning, we tested this model in two subsamples from Experiment 1. We proposed to the first subsample a cognitive problemsolving training and to the second subsample a crossword puzzle activity. We chose the crossword puzzle because we thought it would be interesting to assess whether a widely used leisure activity could have a similar impact on cognition as a problem-solving training. To ensure that solving crossword puzzles remained 
a leisurely activity, in keeping with the spirit of a pastime and to be assessed accordingly, puzzle solving occurred at the participants' homes in an atmosphere that respected the friendly environment in which this activity is usually performed.

\subsection{Methods}

\subsubsection{Participants}

Since cognitive training is a timeconsuming procedure, we chose to minimize the number of individuals included in each subsample. To quantify this minimum number, we referred to Cohen (1992) who indicated the minimum sample size to consider when testing a model with PLS-SEM. This number was set at $n=16$ per group. Two groups were included in experiment 2 so that 32 subjects were selected from the first experiment, i.e., from the 83 participants. The 32 subjects were semirandomly selected to match the 2 groups, problem-solving training and crossword groups, based on age and sex. Sixteen participants (age means $\pm \mathrm{SD}=25.25 \pm 1.61$ years, $M / F=6 / 10$ ) were allocated to the problem-solving training group. As such, they were invited to take part in two training sessions per week for a period of 12 weeks, i.e., 24 training sessions. Each session lasted approximately 1 hour and was performed individually under the supervision of a neuropsychologist. Sixteen participants (age means $\pm \mathrm{SD}=28.42 \pm 0.21$ years, $\mathrm{M} / \mathrm{F}=5 / 10$ ) were allocated to the crossword activity group. Note that one subject left the study before the end. All the participants executed the same sets of puzzles. This group was assigned the same number, frequency, and duration of sessions as the problem-solving group. Participants had previously not solved or very rarely solved crossword puzzles. Neither group differed significantly $(p>0.05)$ with respect to age and sex.

\subsubsection{Training}

\subsubsection{Problem-solving training}

The subjects solved between 120 and 150 closed-ended problems during training from a library of approximately 400 problems (see examples in supplemental material). This allowed us to customize the problems according to the subjects' abilities. Thus, some problems were common to all subjects, and others were specifically targeted to train a particular cognitive weakness in the subject. All in all, subjects solved an average of 5 problems per session. Some of these closed-ended problems were simple, while others were more complex. A simple closed-ended problem is a problem that has one right answer and one method by which this answer could be obtained. Finding the derivative of an algebraic expression is such a problem. In terms of the problem-solving taxonomy, simple closed-ended problems are solved primarily by diagnosis and routine. A complex closed-ended problem is a problem that has only one right answer but several methods to obtain this answer, and solving such problems requires using routines, diagnosis, and several strategies.

At the beginning of the training, the proposed problems were simple closed-ended problems, with the objective of providing an overview of the subject's ability to generate and use routines. However, a simple closed-ended problem generally requires a very simple interpretation step and a simple diagnosis that leads to the selection of a routine. We did not intend for the trained subject to become an expert in a particular routine or diagnosis, which is why we rapidly focused on complex close-ended problems that were sufficiently complex to cause the subject problem-solving difficulties.

In this context, we provided our training procedure to advance subjects. We wanted to increase subjects' practice in many areas of problem solving, with a focus on the nonroutine areas where the teaching of routines is necessary. Thus, we helped the subjects develop rules and formalized methods wherever possible, and then the subjects were expected to identify the best routine among those learned and to use the chosen routine accurately and quickly. We anticipated that this procedure might enable subjects to become 
more efficient and fluent in their problemsolving strategies. Hence, we asked subjects to describe several possible attack plans, with advantages and disadvantages for each, and at the end, subjects decided on one and defended their choice. Care was taken to ensure that the subject was aware of the decisions that they made and the reasons behind the decisions.

Throughout our training procedure, we first invited the subjects to clearly define the goal and identify relevant clues in the instructions that would provide them with key elements to reach this goal. Second, we encouraged the subjects not to limit the number of operators used to establish in the problem space to avoid imposing constraints derived from the interpretation of instructions. Thus, if a subject consistently failed to solve the problem, despite the use of the procedure, we did not limit his reasoning. Third, we ensured that the subjects produced relevant planning steps and, in particular, intermediate planning steps that were essential for solving the problem. Finally, we developed the cognitive flexibility of the subjects with regard to the use of strategies. We encourage the subject to review different solutions and to inhibit known strategies that do not work to facilitate the emergence of new strategies. Indeed, the cognitive flexibility will allow us to get out of the heuristics and to produce new solutions adapted to the context. We believe it can promote the use of frame breaking to facilitate the production of new ideas and that it is therefore a key element for the successful resolution of a problem.

\subsubsection{Crossword solving}

French-language crosswords and arrow words were extracted from specialized crossword collections and used as crosswordsolving problems.

Not all the crosswords and arrow words that we used were equally challenging. Indeed, there was a hierarchy of challenges. We designed a program that incorporated 50 arrow words and 50 crosswords. We determined three levels of difficulty (easy puzzle, mediumdifficulty puzzle, and truly difficult puzzle) for both crossword and arrow word puzzles. We classified puzzles from the easiest to the most complicated. The subject was asked to follow this classification when using the puzzles and to solve puzzles twice a week for 1 hour. The subjects were given additional instructions, including not getting stuck on a puzzle if they were unable to finish it, but rather starting another puzzle and returning to the pending puzzle later. We called the subjects by phone every week to ensure that they were solving the puzzles and to ask them to report back on any issues or difficulties. This phone call was also an opportunity to remind the participant to move on to a higher level if the puzzles were too easy or to a lower level if the puzzles were too difficult.

\subsubsection{Cognitive assessments}

The cognitive assessment before problem-solving training and crossword puzzle activity corresponds to the one performed in the first study. Four new insight and four new noninsight problems were used. Three insight problems (Appendix A of Schooler et al., 1993; problem numbers 2, 5, and 6) and one insight and four noninsight problems were selected from websites. Unresolved problems during preassessment were presented again at the post assessment.

\subsubsection{Experimental design}

One month after the participants completed the evaluation, which gave us time to build and evaluate our model, the 31 participants began their respective training or the activity. One month after the end of the training or the activity, participants were reassessed with the same cognitive tasks as those used in the first assessment. The experimental design is described in Figure 2.

\subsubsection{Data analysis}

For data analyses, cognitive performances of the 31 participants before and after training were assessed using PLS-SEM modeling. The measurement model was 
elaborated from the same indicator variables as those of the experiment 1 . Its validity was assessed by internal consistency, convergent validity and discriminant validity. Regarding the structural model, the $\mathrm{R}^{2}$ metric and the effect size $\mathrm{f}^{2}$ were computed. Statistical comparisons of path coefficients were performed using XLSTAT software.

\subsection{Results}

The results of the PLS SEM modeling are shown in Table 3. The measurement model was constructed from data that included the 31 participants and four reflective constructs: inhibition, reasoning, cognitive flexibility, and innovative thinking. The internal consistency measures, as indexed by the composite reliability, ranged from 0.78 to 0.94 , exceeding the recommended threshold value of 0.70 . The convergent validity was above 0.5 except for the reasoning construct. Each item's factor loading was significant $(p<0.05$, data not shown), and all but three were above 0.6.

Regarding the structural model of pretraining data, similar to the results from all 83 subjects in study 1 , the results showed that the model was statistically significant for the 2 groups $\left(\mathrm{F} \geq 7.85, \mathrm{p} \leq 0.002\right.$, with an $\mathrm{R}^{2}$ value $\geq 0.48$ ). All the path coefficients were positive. Only reasoning had a significant influence on innovative thinking $(\beta \geq 0.541, \mathrm{p} \leq 0.007)$. The relationships between innovative thinking and cognitive flexibility or inhibition were weak and nonsignificant $(\mathrm{p} \geq 0.179)$. The effect size revealed a strong effect of reasoning on innovative thinking $\left(\mathrm{f}^{2}=0.41\right)$ and a weak effect of the other 2 paths $\left(f^{2} \leq 0.03\right.$; Table 4$)$.
The results of the multigroup t-test performed on pretraining data yielded no significant difference, indicating that the problem-solving and cross-word groups performed similarly before training and were similar to all 83 subjects. Thus, because the structural model was similar in all groups, one may reasonably postulate that any changes in path coefficients were an effect of the training itself.

Regarding posttraining data, after crossword puzzle activity, the structural model was statistically significant $(\mathrm{F}=6.48, \mathrm{p}=0.009$; $\left.\mathrm{R}^{2}=0.64\right)$. Only reasoning was significant, and this factor was positively correlated with innovative thinking $(\beta=0.652, p=0.008)$ (Fig $3 \mathrm{~A})$. The effect size of each path is displayed in Table 5.

After problem-solving training, the model was statistically significant $(\mathrm{F}=11.33$, $\mathrm{p}=0.001)$ with substantial explained variance $\left(\mathrm{R}^{2}=0.74\right)$. Reasoning had a weak and nonsignificant negative influence on innovative thinking. In this model, only cognitive flexibility was significant, and it was strongly positively correlated with innovative thinking $(\beta=0.747, p=0.001)$ (Fig 3B). The effect size of each path is displayed in Table 5.

Figure 2: Experimental design of training. The subjects of problem-solving training group were invited to take part in two training sessions per week for a period of 12 weeks, i.e., 24 training sessions. Each session lasted approximately 1 hour. The subjects of crossword activity group were assigned the same number, frequency, and duration of sessions as the problem-solving group. The subjects completed the evaluation 1 month before and after the end of the training or the activity. The evaluation lasted 2 weeks. The fMRI session was performed at the end of the evaluation.

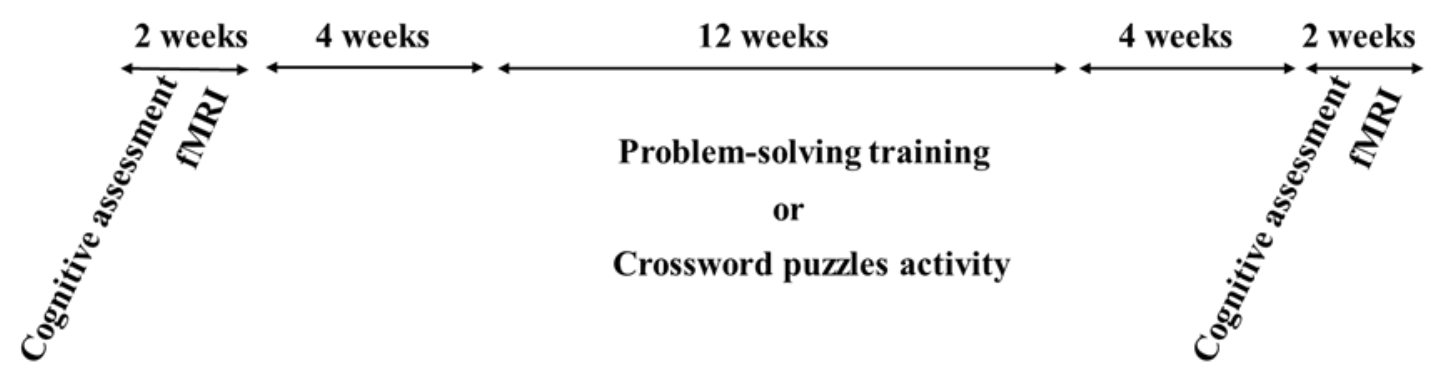




\begin{tabular}{|c|c|c|c|c|c|c|c|}
\hline \multirow[b]{2}{*}{ Constructs } & \multirow{2}{*}{$\begin{array}{c}\text { Composite } \\
\text { reliability }\end{array}$} & \multirow[b]{2}{*}{ Indicators } & \multicolumn{4}{|c|}{ Outer loadings and cross loadings } & \multirow[t]{2}{*}{ AVE } \\
\hline & & & Inhibition & $\begin{array}{l}\text { Cognitive } \\
\text { flexibility }\end{array}$ & Reasoning & $\begin{array}{l}\text { Innovative } \\
\text { thinking }\end{array}$ & \\
\hline \multirow[t]{5}{*}{ Inhibition } & 0.911 & & & & & & 0.769 \\
\hline & & $\begin{array}{r}\text { Stroop, Color } \\
\text { naming }\end{array}$ & 0.922 & 0.028 & 0.385 & -0.319 & \\
\hline & & Stroop, Color name & & & & & \\
\hline & & reading & 0.790 & 0.056 & 0.198 & -0.191 & \\
\hline & & Stroop, Interference & 0.912 & 0.015 & 0.240 & -0.355 & \\
\hline \multirow[t]{7}{*}{ Reasoning } & 0.868 & & & & & & 0.407 \\
\hline & & $\begin{array}{r}\text { Wisconsin, number } \\
\text { of erroneous } \\
\text { answers }\end{array}$ & 0.119 & 0.074 & 0.496 & -0.031 & \\
\hline & & $\begin{array}{r}\text { Wisconsin, } \\
\text { perseverative errors }\end{array}$ & 0.223 & 0.188 & 0.852 & -0.325 & \\
\hline & & $\begin{array}{l}\text { Wisconsin, non- } \\
\text { perseverative errors }\end{array}$ & 0.182 & 0.014 & 0.763 & -0.337 & \\
\hline & & Tower of London & & & & & \\
\hline & & test, 3 moves, time & 0.312 & 0.138 & 0.624 & -0.273 & \\
\hline & & $\begin{array}{l}\text { Tower of London } \\
\text { test, } 4 \text { moves, time }\end{array}$ & 0.212 & 0.151 & 0.547 & -0.114 & \\
\hline \multirow[t]{3}{*}{$\begin{array}{l}\text { Cognitive } \\
\text { flexibility }\end{array}$} & 0.949 & & & & & & \\
\hline & & $\begin{array}{r}\text { Visuospatial focused } \\
\text { attention test, } \\
\text { Variant 3, time }\end{array}$ & 0.045 & 0.955 & 0.120 & -0.209 & 0.904 \\
\hline & & $\begin{array}{r}\text { Visuospatial focused } \\
\text { attention test, } \\
\text { Variant 4, time }\end{array}$ & 0.031 & 0.947 & 0.185 & -0.193 & \\
\hline \multirow[t]{4}{*}{$\begin{array}{l}\text { Innovative } \\
\text { thinking }\end{array}$} & 0.783 & & & & & & 0.538 \\
\hline & & Minnesota test & -0.474 & -0.068 & -0.314 & 0.798 & \\
\hline & & Insight problems & -0.090 & -0.164 & -0.192 & 0.585 & \\
\hline & & $\begin{array}{r}\text { Noninsight } \\
\text { problems }\end{array}$ & -0.105 & -0.265 & -0.347 & 0.797 & \\
\hline
\end{tabular}

Table 3. Assessment of the measurement model: internal consistency (composite reliability), convergent validity (loading and average variance extracted (AVE)), and discriminant validity (cross loading) on pre-training data. 


\begin{tabular}{l|c|c} 
Paths & $\mathbf{f 2}$ & Magnitude of the effect \\
\hline Model of pre-training groups & & High \\
Reasoning on Innovative thinking & 0.41 & Low \\
Cognitive flexibility on Innovative thinking & 0.03 & Low \\
Inhibition on Innovative thinking & 0.02 &
\end{tabular}

Table 4. Effects sizes of the structural model paths on pre-training data.

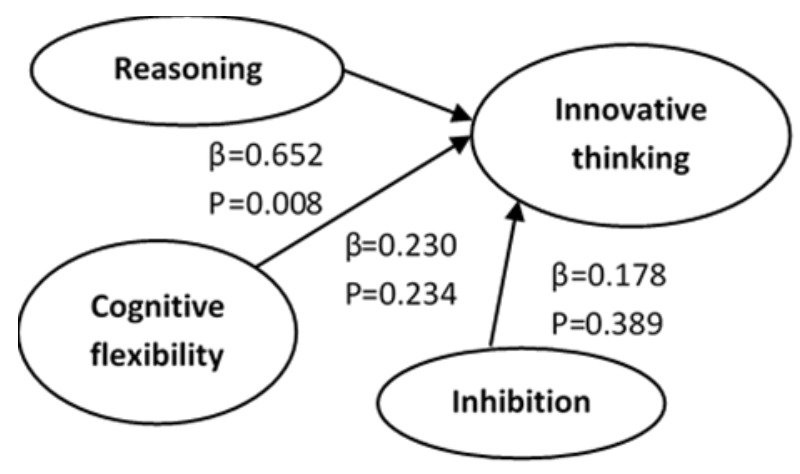

A

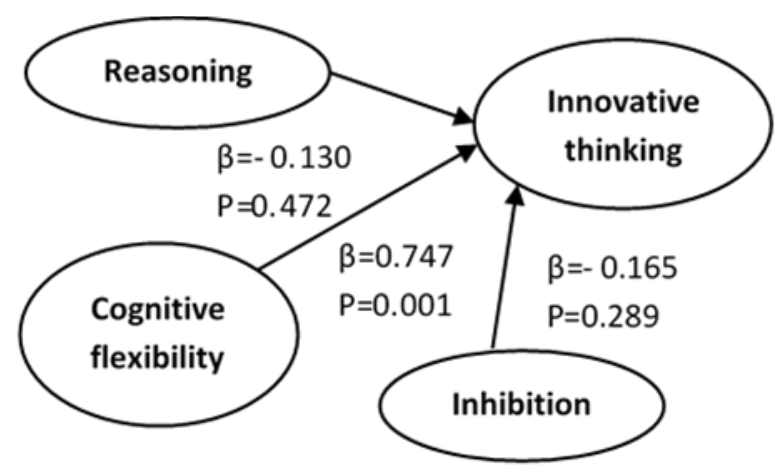

B

Figure 3: Structural model of the direct effects of reasoning, cognitive flexibility, and inhibition on innovative thinking after crossword puzzles activity (A) and problem-solving training (B).

\begin{tabular}{r|c|c} 
Paths & $\mathbf{f 2}$ & Magnitude of the effect \\
\hline $\begin{array}{r}\text { Model of crosswords group } \\
\text { Reasoning on Innovative thinking }\end{array}$ & 0.97 & Substantial \\
Cognitive flexibility on Innovative thinking & 0.14 & Moderate \\
Inhibition on Innovative thinking & 0.07 & Low \\
& & \\
Model of problem-solving training group & & Low \\
Reasoning on Innovative thinking & 0.05 & Substantial \\
Cognitive flexibility on Innovative thinking & 1.51 & Low \\
Inhibition on Innovative thinking & 0.07 &
\end{tabular}

Table 5. Effects sizes of the structural model paths on post-training data.

The results of the multigroup t-test performed on posttraining data showed a significant difference between the crossword and problem-solving groups for the path coefficient related to reasoning-innovative thinking $(\mathrm{t}(29)=2.03 ; \mathrm{p}=0.0)$.

In terms of the composite score calculated by the PLS-SEM analysis for the latent variable 
innovative thinking, Student's t-test analysis yielded that the two groups of participants showed a nonsignificant effect on the pretraining composite score $(\mathrm{t}(29)=0.61$; $\mathrm{p}=0.54$ ) but a significant effect of group on the posttraining composite score $(\mathrm{t}(29)=2.04$; $\mathrm{p}=0.04)$. Problem-solving-trained subjects had higher scores than did the crossword group of subjects.

\section{Experiment 3: Resting state network connectivity}

Given our initial assumption that problemsolving training would improve innovative thinking by changing the way executive processes are involved, we conducted a pilot study only on the 16 participants of the problem-solving group. This pilot study aimed to evaluate to what extent this type of training could induce changes in resting-state functional connectivity. Data in the literature has revealed the important role of resting state functional connectivity in assessing brain changes related to the manifestation of neuronal plasticity (Biswal et al., 2010). Indeed, evaluating this connectivity appears to be a good indicator for highlighting plastic changes following cognitive training. Chapman et al (2015) reported that the benefits of cognitive training led to an increase in resting state brain connectivity in healthy elderly subjects. Cao et al. (2016) showed that following multidomain cognitive training of 24 sessions over a period of 3 months, an increase in resting-state functional connectivity was observed in the default mode network, the salience network, and the central executive network. This increase in connectivity in the healthy elderly was associated with an improvement in language and delayed memory. Similar increase in resting state brain connectivity after cognitive training have been also reported in patients with mild cognitive impairment (MCI) (Styliadis et al., 2014; Kim et al 2020) and after stroke (Lin et al., 2014) suggesting that resting state functional connectivity could be a good marker of cognitive recovery in the clinic. We have just seen in experiment 2 that in subjects trained with problem solving, flexibility was strongly positively correlated with innovative thinking, whereas it was reasoning before training. Given the data in the literature showing changes in resting-state connectivity after cognitive training, we expect here that the change in the involvement of the executive processes in trained subjects will lead to changes in resting-state connectivity.

\subsection{Methods}

\subsubsection{Participants}

The 16 participants were right-handed. Functional MRI acquisitions were completed before and after problem-solving training 15 days after the cognitive assessment.

\subsubsection{Magnetic resonance imaging data}

The 16 subjects were scanned on a 3-Tesla BRUKER MEDSPEC 30/80 MRI scanner equipped with a circular polarized head coil at the MRI Center of La Timone (Center IRMINT@CERIMED, UMR 7289, in Marseille). Subjects were asked to rest with their eyes closed during the scan but not fall asleep. T1 anatomical images and fMRI images were acquired in the axial plane, parallel to the anterior-posterior commissure axis, and covered the whole brain. Whole-brain anatomical MRI data were acquired using a high-resolution structural T1-weighted image (MPRAGE sequence, resolution $1 \times 1 \times 1 \mathrm{~mm}$ ). Resting-state fMRI scans were acquired using a BOLD T2*-weighted echo planar imaging (EPI) gradient-echo pulse sequence with $\mathrm{TR}=2.4 \mathrm{sec}, \mathrm{TE}=30 \mathrm{msec}$, flip angle $=78^{\circ}$, $\mathrm{FOV}=192 \mathrm{~mm}$, voxel size $=3 \times 3 \times 3 \mathrm{~mm}$, matrix $=64 \times 64$, slice thickness $=3 \mathrm{~mm}, 0.75 \mathrm{~mm}$ gap, and 36 slices. The total acquisition time for the fMRI was 10 minutes. A total of 250 volumes were collected for each subject. The first 5 images were discarded to allow for stabilization of the MRI signal, leaving 245 volumes for analysis. The ethical committee of the hospital approved the protocol. All experiments were conducted in accordance with the Declaration of Helsinki. Written informed consent was obtained from all individuals. 


\subsubsection{Data analysis}

The pre- and posttraining MR images were preprocessed using SPM8 software (http://www.fil.ion.ucl.ac.uk/spm/software/sp $\underline{\mathrm{m} 8 /)}$ running in a MATLAB 7.5 environment (Mathworks, Inc., Sherbon, MA, USA). To perform image analysis, the 245 images were first slice-time corrected, realigned to the first image, unwrapped, and then coregistered to structural data. Four datasets that were affected by head movements more than $3 \mathrm{~mm}$ in translation or rotation were rejected. Accordingly, the final population considered for analysis included 12 individuals.

To identify the resting state networks (RSNs) in our subjects, , the pre- and posttraining preprocessed data, of all 12 participants were decomposed using the group spatial independent component analysis (ICA) of the Group ICA of fMRI Toolbox (GIFT v1.3i) (http://icatb.sourceforge. net/) (Calhoun, et al., 2001). This process allowed us to identify the spatial sources of resting state signals. Each independent component (IC) selected was considered to reflect a functional RSN. The Infomax algorithm was computed 10 times with different initial conditions. Twenty spatial ICs were then estimated by a minimum description length criterion. ICAs were performed using the ICASSO function and included 5 iterations. The ICASSO results showed an average Iq of $0.97 \pm 0.007 \mathrm{SD}$, indicating a high stability of the estimated components (Calhoun et al., 2001). The components that were deemed to be artifacts were excluded. Twelve components were retained. To identify the functional networks, the components were visually inspected and compared to descriptions of RSNs previously described in the literature. A template matching procedure was performed (correlation above 0.5), where ICs were compared to templates from the study by Allen et al. (2011). From each IC, the regions of interest (ROIs) were extracted using the GIFT stats utility. This tool allowed us to identify which clusters were statistically significant for each component (the threshold of the onesample t-test against zero was set at $\mathrm{p}<0.05$, with a false discovery rate (FDR) correction for multiple comparisons) and extract the coordinates of these ROIs that formed each RSN. Using the MarsBar toolbox (Brett et al., 2002), spherical ROIs were created with a radius of $6 \mathrm{~mm}$ and centered on the Montreal Neurological Institute coordinates of the cluster peaks. These ROIs were then used for functional connectivity and graph theoretical analyses.

Functional connectivity analyses were performed using the Functional Connectivity (CONN v15 h) toolbox, which included an ROI-based correlation analysis (http://web.mit.edu/swg/software.htm;

Whitfield-Gabrieli and Nieto-Castanon, 2012). Preprocessed images were bandpass filtered at $0.01 \mathrm{~Hz}-0.08 \mathrm{~Hz}$ to reduce the effect of lowfrequency drift and high-frequency noise. Realignment parameters were defined as firstlevel covariate confounds. White matter, cerebrospinal fluid motion, and Artifact Detection Tools (ART) outliers were taken as confounds (Behzadi et al., 2007). Correlation coefficients were calculated between each pair of ROIs in each network. The toolbox performed the first-level general linear model test to determine the correlation connectivity at the individual level. Correlation coefficients were then converted into z-scores, and a paired t-test was used to determine significant connections between pre- and postsessions in the problem-solving trained participants, with a threshold set at $\mathrm{p}<0.05$ FDR-corrected.

Graph theoretical analysis was performed to further evaluate the features of the RSNs using the CONN v15 toolbox. According to graph theory, brain networks can be described as graphs composed of nodes (ROIs), with edges (functional connections) among the nodes (Watts and Strogatz, 1998). The time series of the low-frequency BOLD signals were extracted for each of the ROIs and averaged over all voxels in each node. For each subject, an undirected correlation matrix (Pearson) was computed. To compare the groups, the CONN default setting 'cost' (connection density) was chosen and set at a threshold of 0.15 (Bassett and Bullmore, 2006), meaning that $15 \%$ of all the possible edges in the network were present. Topological properties, which included measures such as degree, local efficiency, and 
global efficiency, were then evaluated. Degree is a measure of the number of connections of a node. Local efficiency measures how efficiently the network exchanges the information at the clustering level; it is computed on node neighborhoods and is related to the clustering coefficient, which is a measure of the degree to which nodes in a graph form a cluster. Global efficiency measures how efficiently the network exchanges information at the global level. This metric is inversely related to the characteristic path length, which describes the number of edges between one node and any other node in a network and provides an overview of the effectiveness of information transfer (Bassett and Bullmore,
2006). Graph theoretical metrics were thresholded at $\mathrm{p}$-FDR $<0.05$ in a two-sided analysis.

\subsection{Results}

The results of the ICA analyses on the problem-solving group that showed a spatial network structure are displayed in Fig. 4.

Table 6 provides details on the brain regions of each IC. Of the 12 ICs selected, IC09, 18, and 20 were considered part of the DMN. IC07, 10, and 13 are related to $\mathrm{AN}$. The visual network (VN) is represented in two group-level ICs, IC01 and 06. IC03, 05, 16, and 19 correspond to the SMN.
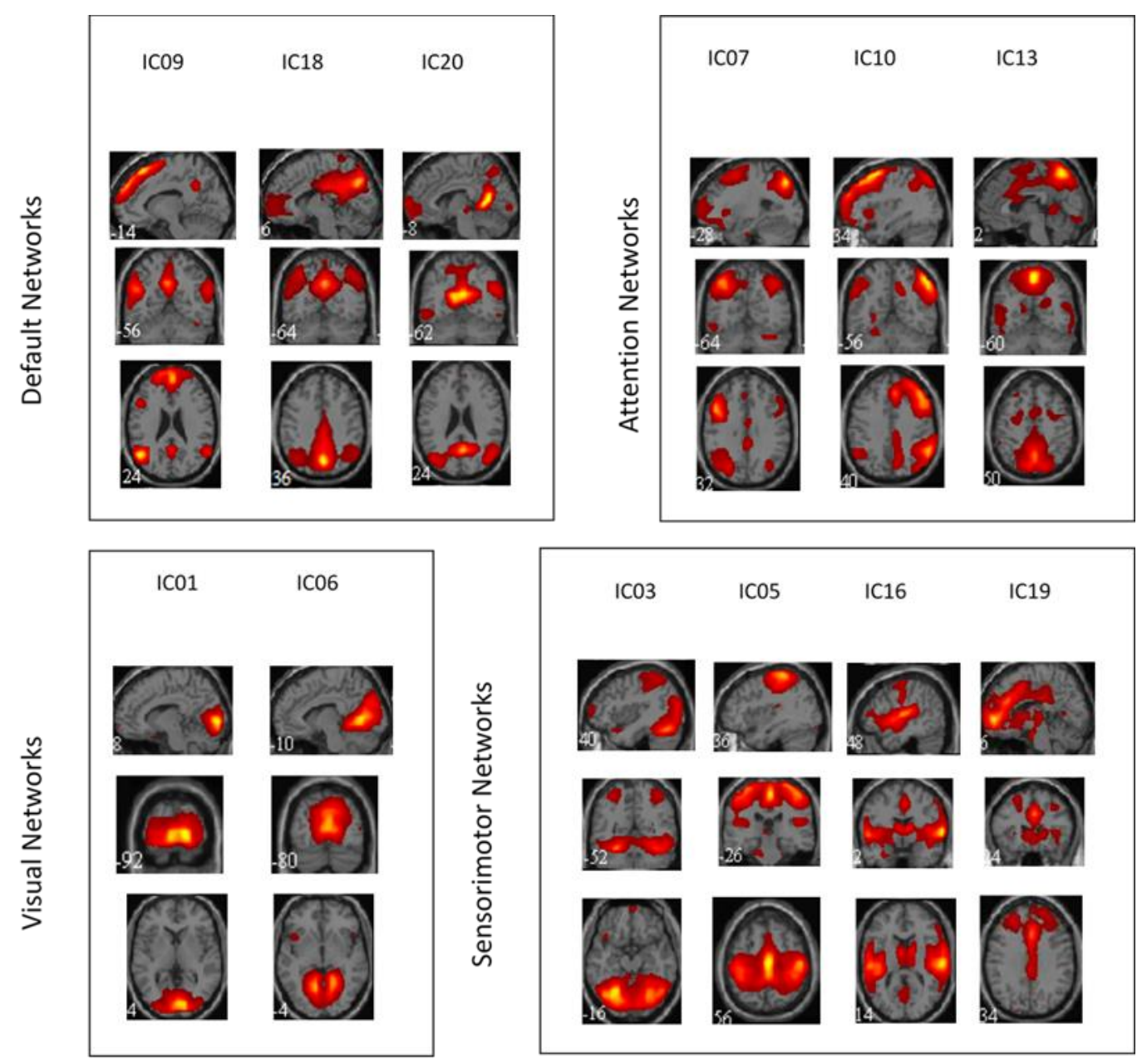

Figure 4. Depiction of the twelve Resting State Networks (RSN) identified by Independent Component Analysis (ICA). The RSNs are grouped into four categories based on their relation to reference networks - default mode, attention, visual, and sensorimotor networks. All images were thresholded at $\mathrm{p}<0.05$ (FDR-corrected). 


\begin{tabular}{|c|c|c|c|c|c|}
\hline RSN & Name & $\mathbf{x}$ & y & $\mathbf{z}$ & $\begin{array}{c}\text { Maximal } \\
\text { voxel t- } \\
\text { value }\end{array}$ \\
\hline \multicolumn{6}{|l|}{ DMN } \\
\hline \multirow[t]{3}{*}{ ICO9 } & Left Precuneus & -3 & -57 & 30 & 15.20 \\
\hline & Left Superior Medial Gyrus & 0 & 57 & 21 & 25.98 \\
\hline & Right Precentral Gyrus & 39 & -12 & 54 & 5.23 \\
\hline \multirow[t]{4}{*}{ IC18 } & Left Angular Gyrus & -45 & -66 & 33 & 30.12 \\
\hline & Right Middle Frontal Gyrus & 36 & 18 & 39 & 7.60 \\
\hline & Right Precuneus & 12 & -63 & 30 & 25.43 \\
\hline & Right Superior Frontal Gyrus & 24 & 69 & 9 & 7.97 \\
\hline \multirow[t]{2}{*}{ IC20 } & Left Superior Frontal Gyrus & -24 & -3 & 57 & 10.57 \\
\hline & Right Superior Frontal Gyrus & 27 & 27 & 51 & 12.23 \\
\hline \multicolumn{6}{|l|}{$\begin{array}{l}\text { Attentional } \\
\text { Network }\end{array}$} \\
\hline \multirow[t]{8}{*}{ ICO7 } & Left Fusiform Gyrus & -30 & -12 & -33 & 8.91 \\
\hline & Left Inferior Frontal Gyrus (p. Triangularis) & -45 & 24 & 21 & 21.84 \\
\hline & Left Inferior Temporal Gyrus & -51 & -42 & -15 & 10.02 \\
\hline & Left Posterior Cingulate Cortex & 0 & -33 & 33 & 9.98 \\
\hline & $\begin{array}{l}\text { Right Inferior Frontal Gyrus (p. } \\
\text { Triangularis) }\end{array}$ & 51 & 24 & 27 & 5.56 \\
\hline & Right Inferior Parietal Lobule & 42 & -51 & 45 & 16.95 \\
\hline & Right Inferior Temporal Gyrus & 63 & -48 & -15 & 14.74 \\
\hline & Right Middle Cingulate Cortex & 0 & -3 & 30 & 10.88 \\
\hline \multirow[t]{4}{*}{ IC10 } & Left Inferior Parietal Lobule & -54 & -54 & 36 & 11.78 \\
\hline & Right Inferior Parietal Lobule & 57 & -51 & 42 & 39.07 \\
\hline & Right Middle Temporal Gyrus & 66 & -36 & -9 & 8.41 \\
\hline & Right Superior Orbital Gyrus & 18 & 15 & -21 & 7.14 \\
\hline \multirow[t]{6}{*}{ IC13 } & Left Fusiform Gyrus & -36 & -36 & -18 & 7.76 \\
\hline & Left Insula Lobe & -39 & 3 & 3 & 8.19 \\
\hline & Left Middle Frontal Gyrus & -27 & 39 & 36 & 7.27 \\
\hline & Left Middle Temporal Gyrus & -54 & -60 & -3 & 12.01 \\
\hline & Right Insula Lobe & 45 & 12 & 3 & 12.73 \\
\hline & Right Middle Frontal Gyrus & 39 & -12 & -21 & 6.81 \\
\hline \multicolumn{6}{|l|}{$\begin{array}{l}\text { Visual } \\
\text { Network }\end{array}$} \\
\hline ICO1 & Left Lingual Gyrus & -9 & -93 & -15 & 16.44 \\
\hline \multirow[t]{5}{*}{ ICO6 } & Area 17 & -12 & -87 & 3 & 17.19 \\
\hline & Left Inferior Parietal Lobule & -42 & -27 & 36 & 7.75 \\
\hline & Left Middle Occipital Gyrus & -39 & -69 & 6 & 6.99 \\
\hline & Left Middle Temporal Gyrus & -60 & -33 & 6 & 8.95 \\
\hline & Right Middle Temporal Gyrus & 51 & -69 & 6 & 12.90 \\
\hline
\end{tabular}




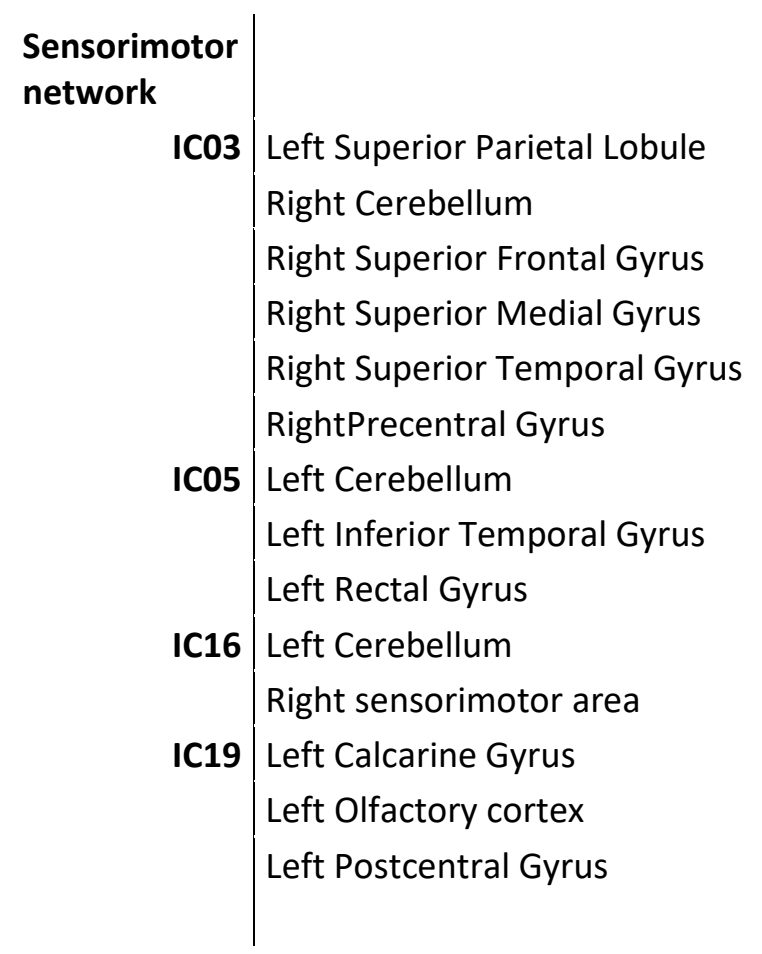

$\begin{array}{cccc}-21 & -69 & 51 & 14.80 \\ 24 & -60 & -21 & 22.90 \\ 33 & 60 & 15 & 6.01 \\ 3 & 63 & 30 & 6.96 \\ 54 & -30 & 3 & 6.32 \\ 60 & 6 & 33 & 5.73 \\ -12 & -39 & -27 & 9.57 \\ -42 & -36 & -24 & 6.32 \\ -6 & 15 & -21 & 10.00 \\ -18 & -69 & -21 & 8.74 \\ 3 & -18 & 51 & 11.84 \\ -3 & -60 & 12 & 4.95 \\ -6 & 24 & -6 & 20.22 \\ -36 & -42 & 60 & 5.83\end{array}$

Table 6. Independent component analysis (ICA) results. The table lists brain peak $\mathrm{x}, \mathrm{y}, \mathrm{z}$ coordinates in MNI stereotaxic space for each separate brain region, anatomical labels, and $t$ statistics from the one sample t-tests that determined the spatial structure of each network. Results were thresholded at $\mathrm{p}<0.05$ (FDR-corrected).
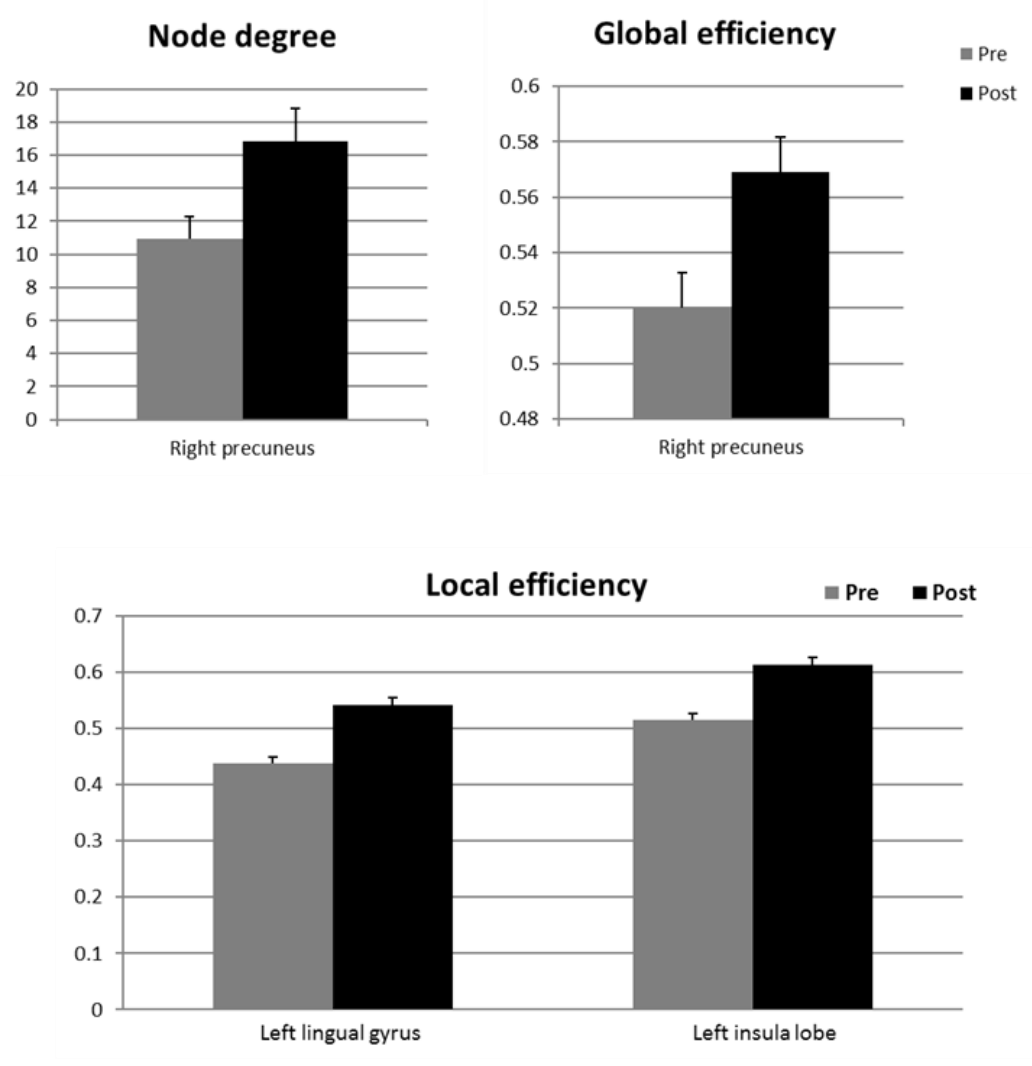

Figure 5. Mean and SEM values for nodal metrics in regions with statistically significant group differences $(\mathrm{p}-\mathrm{FDR}<0.05)$ between pre- and post-problem-solving training. 
Functional connectivity analyses before and after problem-solving training revealed significant changes in the $\mathrm{AN}$ and $\mathrm{VN}$ (p-FDR $\leq 0.05)$. Within the AN, functional connectivity increased between the right inferior frontal gyrus and the left fusiform gyrus following training $(\mathrm{t}(11)=4.21 ; \mathrm{p}$ FDR=0.024). Within the VN, the left middle occipital gyrus demonstrated significantly higher connectivity with the left lingual gyrus $(\mathrm{t}(11)=3.67 ; \mathrm{p}-\mathrm{FDR}=0.018)$ and the left middle temporal gyrus $(\mathrm{t}(11)=3.01 ; \mathrm{p}$ $\mathrm{FDR}=0.03$ ) following problem-solving training. Within the DMN, functional connectivity increased between the right precentral gyrus and the right precuneus but did not reach a significant $\mathrm{p}$-FDR-corrected threshold $(\mathrm{t}(11)=2.92 ; \mathrm{p}-\mathrm{FDR}=0.12$ and $\mathrm{p}$ uncorrected $=0.014)$. Similarly, a nonsignificant decrease in connectivity strength between the right precentral gyrus and the right middle frontal gyrus was noted following problem-solving training $(\mathrm{t}(11)=-$ 2.30: $\mathrm{p}-\mathrm{FDR}=0.23$ and $\mathrm{p}$-uncorrected $=0.041$ ). Within the SMN, no significant connectivity values were noted.

The results of the graph theoretical analyses are shown in Fig. 5. Network properties at the global level showed no significant differences when compared before and after problem-solving training. In contrast, we found significant differences in network properties at the nodal level. With the FDR-corrected significance threshold, differences in nodal metrics were found in node degree and local and global efficiencies. Following problem-solving training, participants demonstrated increased node degree $(\mathrm{p}-\mathrm{FDR}=0.01)$ and global efficiency (p-FDR=0.006) in the right precuneus, which belongs to the DMN. Local efficiency values for the left lingual gyrus, which belongs to the $\mathrm{VN}$ (p-FDR=0.04), and the left insular lobe, which belongs to the AN (p-FDR=0.03), increased following problem-solving training.

\section{Discussion}

This study examined whether problem-solving training modifies cognitive functioning and relates to resting-state functional connectivity changes in healthy adult subjects. Data analyses of cognitive measures using PLS-SEM showed that innovative thinking was influenced by reasoning in nontrained subjects, whereas innovative thinking was influenced by cognitive flexibility following problemsolving training. Thus, we argue that a cognitive intervention based on problem solving promotes innovative thinking by changing the way subjects recruit and use relevant cognitive processes to cope with the demand.

\subsection{Effect of problem solving training on innovative thinking}

The PLS-SEM modeling used in the present study emphasized insight and noninsight problems, both of which are associated with the same latent variable of innovative thinking. Insight is often defined as a subjective feeling of a sudden understanding that accompanies problem solving (Webb, Little \& Cropper., 2016; Weisberg, 2014). This feeling could be due to the existence of unconscious processes, which suggests that critical steps in insight solutions are not reported (Kaplan \& Simon, 1990). Work by Schooler et al. (1993) showing evidence that processes associated with insight problem solving are not available in a verbal report agrees with this interpretation. In contrast, according to Bowden (1997), noninsight problems are solved through the use of knowledge and logical deductions. However, Metcalfe and Wiebe (1987) believe there is a very fine distinction between insight and noninsight problems and this view is confirmed by Weisberg (2014), reporting that insight and noninsight problems can be solved with both processes (i.e., insightful or analytic). Therefore, it is essential to receive feedback from the problem solver on the processes used to solve a problem to better understand the underlying processes. 
A single problem task can be used as an indicator of both insightful and noninsightful problem solving. In these cases, the feelings of the subject determine how the problem is solved (i.e., insightful or analytic). Considering these issues, in the present study, we systematically asked the subjects how they resolved the problem and what their feedback was regarding feeling or the occurrence of insights. This is an important point to consider when interpreting the effects of our training, i.e., which aspects have been influenced by changes in the recruitment of cognitive functions and their involvement in innovative thinking. Note that only noninsight problems were used in our training. Having trained the subjects with these problems, we know that these problems were resolved through the generation and use of routines, as well as through the use of conscious strategies. However, toward the end of the training, we noted that subjects showed greater abilities to use particular strategies spontaneously and therefore without necessarily being aware of their choice.

Thus, training with complex closedended problems appeared to facilitate problem solving through the experience of insight. We believe that this facilitation was possible via the strengthening of cognitive flexibility, which played a leading role during training. The problems used in our training program were chosen to be sufficiently complex to cause the subject serious difficulty, such that they failed. We then increased subjects' practice in many areas of problem solving, with a focus on nonroutine areas. We insisted on the advantages of not limiting reasoning and using frame breaking to facilitate the production of new solutions. Moreover, the use of a large number of problems allowed us to emphasize fluency in strategies. Finally, care was taken to ensure that the subject was aware of the decisions they made and the reasons behind them. The goal was for the subject to memorize as many strategies as possible such that they created a library from which they could draw ideas or processes to solve future problems. Once this library was created, we trained subjects on the flexible implementation of various strategies.

This procedure may have facilitated the elaboration of unconscious inference processes that produced insight solutions. Our training procedure could contribute to the unconscious activation of critical steps by strengthening processes involved in innovative thinking, such as juggling opposing thoughts (induction and deduction), reversal (flipping assumptions), recombination and rearrangement, and reencoding, which involve changes in perceptual interpretations and facilitate frame breaking.

In contrast to the problem-solving training, the crossword puzzles activity did not modify the way the subjects worked, since, after crossword puzzles activity, reasoning is still the most important factor in influencing innovative thinking. Thus, the practice of this leisure activity, whose controlled parameters are similar to problemsolving training, are frequency, duration and increase in the level of difficulty to maintain the challenging aspect, is not sufficient to promote innovative thinking.

\subsection{Effect of problem solving training on resting state functional connectivity}

Successful problem-solving training seemed to have an effect on regional functional connectivity in brain networks involving the DMN, the $\mathrm{AN}$, and the $\mathrm{VN}$. Changes in the connectivity of resting statenetworks following problem-solving-based training corroborate studies using different cognitive training programs (Jolles et al., 2013; Cao et al., 2016; Chatman et al., 2017; Fink et al., 2015; 2018). In studies conducted by Fink et al., these brain changes occurred after 3 weeks of verbal divergent thinking training consisting of 144 exercises organized in 18 training modules of 20 minutes each. For these authors, as exposures occur, the subject will refine his strategy until his potential is fully optimized, which will lead to changes in brain function. These modifications could reflect changes in the brain assessed by 
resting-state functional connectivity. We used a similar number of exercises (between 120 and 150 closed-ended problems) and training sessions (24 training sessions). However, our training was more widely distributed, with two sessions per week compared to six sessions per week in the study by Fink et al. Although the nature of the training was different between the two studies, our results support the idea that training must be long enough to cause changes in the resting state connectivity. We observe these changes 6 weeks after training indicating that they can be maintained over time. This result is in agreement with data from Cao et al. (2016) showing changes in brain connectivity up to 1 year after training.

\subsubsection{Default mode network}

Graph theory analysis highlighted the right precuneus within the DMN as having an increased degree and global efficiency in participants who underwent problem-solving training. These results indicate that in problem-solving-trained subjects, the right precuneus is more connected to the rest of the network. Since global efficiency is mainly influenced by short paths (Rubinov and Sporns, 2010), the connections of the right precuneus are intended to be with its closest regions. Such short path lengths are believed to promote functional integration since they allow communication with few intermediate steps and thus minimize the effects of noise (Sporns and Honey, 2013). The right precuneus is a major node in the main functional and structural networks of the human brain (Hagmann et al., 2008) with a relevant role within the DMN (Utevsky et al., 2014). The precuneus is primarily involved in the retrieval of information from working memory or episodic memory, especially the retrieval and processing of spatial images, visuospatial imagery, and self-processing operations (Cavanna and Trimble 2006). The precuneus is also a critical brain region in insight processing. Luo (2004) demonstrated that answers requiring the breaking of mental sets and the transformation of conventional thinking significantly activated the right precuneus. Based on this literature, we can reasonably believe that the change in precuneus connectivity may be due to the work done during our training.

\subsubsection{Attentional network}

With respect to the attentional network, we showed increased functional connectivity between the left fusiform gyri and the right lower frontal gyri. The fusiform gyrus is an integral part of the ventral occipitotemporal junction, a region that is widely involved in cognitive processes such as the perception of faces, objects, places, or words. Interestingly, many studies have shown that activation in the fusiform gyrus is associated with insight tasks (Qiu et al., 2010; Zhang et al., 2011). Shen et al. (2013) argued that the fusiform gyrus is involved in the formation of new images and remote associations based on visual imagery. Based on these findings, the modification of the connectivity of the left fusiform gyrus after problem-solving training could reflect a shift toward a new way of thinking that is less governed by language and more focused on images and mental imagery. Some studies attribute mental imagery to a potentially influential role in creativity (Martindale, 1990; Leboutillier and Marks, 2003; Kozhevnikov et al., 2013). It could therefore be that problem-solving training has promoted this shift toward mental imagery, which in turn has fostered innovative thinking in trained subjects by making them more flexible. In line with this hypothesis, after training, the problem-solving group showed an improved score on the Minnesota task, a measure of the latent factor of innovative thinking, thus favoring this hypothesis. Indeed, this task mainly requires imagery capacity, spatial observation, mental visualization skill, and the ability to visualize and manipulate objects in space. The inferior frontal gyrus is reported to play a diverse role in evaluating the potential relevance of sensory stimuli and in inhibiting inappropriate responses (Konishi et al., 1999). Aron et al. (2004) indicated that only the right inferior frontal gyrus is involved in the inhibition of inappropriate responses. Evidence exists to show that inhibitory control can support 
creativity (Storm and Angello, 2010; Cassotti et al., 2016). Kleibeuker et al. (2013) reported activation of the inferior frontal gyrus in subjects who provided optimal solutions to creative problems, and Shen et al. (2016) reported strong activation of the right inferior frontal gyrus during a compound remote association task related to creative thinking. Thinking about something new and original requires inhibiting the first solutions that come to mind to be able to explore new ideas later on. Our problem-solving training involved complex closed-ended problems that require several methods and strategies to be resolved. The variety of the problems used during the training makes the subject regularly find new strategies and thus get off the beaten track to solve the problem correctly, which implies regularly inhibiting spontaneous strategies that first come to mind. Thus, the increased connectivity between the left fusiform gyrus and the right inferior frontal gyrus during the resting state supports the idea that the greater ability of trained subjects to develop innovative thinking relies on the relevance of the stimuli and the inhibition of inappropriate responses, on the breaking of mental sets and restructuring, and on the facilitation of the original images and remote associations based on visual imagery.

Graph theory analyses performed within the AN indicated an increase in local efficiency in the left insular lobe after problem-solving training. The insula is a brain structure involved in disparate cognitive, affective, and regulatory functions that is involved in the psychological processes that underlie emotional experience, working memory, and attentional shift. In the model developed by Menon and Uddin (2010), the insula facilitates bottom-up access to the brain's attentional and working memory resources. The left insula is also involved in serial processing; it is sensitive to salient environmental events and marks such events in time and space for further processing. The role of the insula may be associated with the "Aha!" experience and the interactions between cognition and emotion in insight problem solving (Luo et al., 2004); however,
Aziz-Zadeh et al. (2009) reported that the left insula was also activated during routine problem solving. Increases in insular local efficiency, a measure of integration among neighbors of a node, suggest that in participants trained for problem solving, the insula is embedded within a richly connected environment. In other words, the cognitive processes associated with training have allowed the insula to take a more central position in the network. The involvement of the attention network, with an emphasis on the left fusiform gyrus, the right inferior frontal gyrus, and the left insular lobe, can explain the cognitive results found in the PLS-SEM analysis, which showed changes in cognitive functioning in favor of cognitive flexibility in the promotion of innovative thinking.

\subsubsection{Visual network}

The visual network includes regions of the occipital lobe (lingual and middle occipital gyri and area 17), inferior parietal lobule, and middle temporal gyrus bilaterally. The functional connectivity analysis revealed an increase in connectivity between the left middle occipital gyrus, the left middle temporal gyrus and the left lingual gyrus as a result of problem-solving training. The occipitotemporal functional connection indicates involvement of the ventral visual pathway (Goodale, 2011). As argued by Kravitz et al. (2013), the ventral pathway is implicated in the formation of specific representations or associations involving stable stimuli from visual information. Consistent with this hypothesis, it can be proposed that the processes associated with our training program stimulated many stable visual configurations from complex closedended problems. The lingual gyrus is located near the ventral visual pathway, and it plays a vital role in vision and dreaming (Dresler et al., 2015; Luo et al., 2013). This region also stimulates and redirects problem space when there is a need to link original connections between different representations of a heuristic prototype and a target problem. More specifically, research has shown that the lingual gyrus is associated with visual memory (Bogousslavsky et al., 1987), vivid 
visual imagery (Belardinelli et al., 2009), and motion imagery (Malouin et al., 2003). In addition, the lingual gyrus works with the cuneus in visuospatial ability, somatosensory stimulation, and perception of sensory stimuli (Kong et al., 2009). Graph theory analysis reinforced the involvement of the lingual gyrus within the visual network. Indeed, we have shown that the local efficiency of this region increased as a result of problemsolving training, suggesting that among the trained participants, the neighboring regions of the left lingual gyrus were highly interconnected. Thus, the activation of the lingual gyrus may help recover heuristic knowledge that facilitates the formation of new nonverbal information. The left middle temporal gyrus is involved in declarative memory (Squire et al., 2004) and belongs to the semantic system involved in storage and retrieval of semantic information. Interestingly, Fink et al. (2015) reported an activation of the left middle temporal gyrus during the practice of the instance task that consisted of fluently generating common and typical conditions or facts applied to a given adjective without originality instruction after training of verbal creativity. In contrast, low activation in the left middle temporal gyrus is associated with the Alternative Uses Task (AUT) after the same training. In view of these data, one possible interpretation of our results would be that the increased connectivity between the left middle occipital gyrus, the left middle temporal gyrus and the left lingual gyrus as a result of problemsolving training may reflect improved retrieval from declarative memory, which fosters a more effective use of generation strategies from semantic, visual, and visuospatial information.

\subsection{Limitations}

There are some methodological limitations to the interpretation of our data. First, although the protocol of the trained group and the control group was similar in terms of the number of sessions, duration, etc., these two groups differed in terms of contact with the experimenter. This is a choice we made because we wanted to compare our problem-solving training with leisure activity training in an ecological context, but it is likely that this difference influenced our results. If this is the case, we are not able to assess the impact of this difference. Second, we did not have a control group to compare the fMRI data we obtained in trained subjects. Therefore, we cannot argue that the brain changes obtained are specific to our problem solving training. Finally, the size of our trained group is small. The interpretation of our data must therefore be considered with caution because our results will have to be confirmed with a larger population.

\subsection{Conclusion and future directions}

Overall, we reported that a cognitive intervention based on complex closed-ended problem solving improved innovative thinking by changing the way the subjects recruit and use relevant cognitive processes to cope with the demand. Improved innovative thinking was reflected in trained subjects by a strengthening of mental flexibility. Our fMRI data showed that this change was underpinned by a modification in the regional connectivity of brain networks at rest that are involved in creative processes. These connectivity modifications indicate that changes in the way of thinking of trained subjects would occur through nonverbal information, including visual and visuospatial information and mental imagery. These results are promising for the development of new interventions that can help healthy or pathological individuals cope with the challenges of their daily lives. These results may even have applications in education. Future studies should confirm the effectiveness of this type of training in an ecological environment and determine how it can be judiciously integrated into holistic rehabilitation in patients with pathologies to promote a transfer of rehabilitation into everyday life. The study of cerebral connectivity at rest will be quite helpful in understanding how brain networks are restructured after cognitive functioning reorganization. Assessing whether this 
restructuring of networks is sustainable for a long period of time will then be essential. It will also be necessary in the future to assess the specificity of changes in brain connectivity at rest. Indeed, while there is no doubt that these changes are due to problemsolving training, we do not know whether these changes, some of them or others would occur after crossword solving activity. It would then be interesting to evaluate the effects of crossword puzzle training with the same coaching done by the experimenter as the one we tested in the problem-solving training. Answering this question would allow us to distinguish cognitive processes and related brain changes common to both trainings from those specific to each of them. Perhaps this would also allow us to highlight an effective training method that would stimulate innovative thinking using various types of content.

\section{Acknowledgments}

This work was supported by the Centre National de la Recherche Scientifique (CNRS), Aix-Marseille University (AMU), and by grant PDH-1-SMO1-0203 from DGA.

\section{References}

Alescio-Lautier, B., Sambuchi, N., Michel, B.F., \& Chambon, C. (2019) Can multifactorial cognitive training slow down the cognitive decline in early Alzheimer patients? Journal of Alzheimer's Disease \& Parkinsonism. 9 (4), 470.

Allen, E.A., Erhardt, E.B., Damaraju, E., Gruner, W., Segall, J.M., Silva, R.F., et al. (2011). A baseline for the multivariate comparison of resting-state networks. Front Syst Neurosci, 5, 2. doi: 10.3389/fnsys.2011.00002. eCollection 2011.

Aron, A.R., Monsell, S., Sahakian, B.J., \& Robbins, T.W. (2004). A componential analysis of task-switching deficits associated with lesions of left and right frontal cortex. Brain, 127, 1561-1573.
We thank the European Centre for Research in Medical Imaging (CERIMED) in Marseilles (France) for their technical assistance.

\section{Author contributions}

B.A.L., C.C. and M.H.F conception and design of research; B.A.L., C.D. and C.C. performed the experiments; G.E. computer development of cognitive tasks; J.L.A. fMRI acquisition sequences, VP analyzed data and prepared figures; B.A.L. and V.P. interpreted results of experiments and wrote the manuscript.

\section{Declaration of interest}

The authors declare that the research was conducted in the absence of any commercial or financial relationships that could be construed as a potential conflict of interest.

The opinions or assertions expressed herein are the private views of the authors and are not to be considered as official or as reflecting the views of the French Military Health Service.

Aziz-Zadeh, L., Kaplan, J.T., \& Iacoboni, M. (2009). "Aha!": The neural correlates of verbal insight solutions. Hum Brain Mapp, 30, 908-916. doi: 10.1002/hbm.20554.

Ball, K., Berch, D,. Helmers, K.F., Jobe, J.B., Leveck, M.D., Marsiske, M., et al. for the ACTIVE group (2002). Effects of cognitive training interventions with older adults. A randomized controlled trial. Journal of the American Medical Association, 288, 2271-2281.

Ball K., Edwards J.D., \& Ross L.A. (2007). The impact of speed of processing training on cognitive and everyday functions, Journal of Gerontology, series B, Psychological Sciences and Social sciences, 62, 19-31.

Baruah J \& Paulus P.B. (2008) Effects of Training on Idea Generation in Groups. Small Group Research, doi:10.1177/1046496408320049 
Bassett, D.S., \& Bullmore, E. (2006). Smallworld brain networks. Neuroscientist, 12, 512-523. $10.1177 / 1073858406293182$

Behzadi, Y., Restom, K., Liau, J., \& Liu, T.T. (2007). A component based noise correction method (CompCor) for BOLD and perfusion based fMRI. Neuroimage, 37, 90-101.

Belardinelli, P., Ciancetta, L., Staudt, M., Pizzella, V., Londei, A., Birbaumer, N., et al. (2009). Motor control in young patients with unilateral brain lesions: an MEG study. Cogn Process, 10, 185-188. doi: 10.1007/s10339-009-0282-y.

Belleville, S., Gilbert, B., Fontaine, F., Gagnon, L., Ménard, E., \& Gauthier, S. (2006). Improvement of Episodic Memory in Persons with Mild Cognitive Impairment and Healthy Older Adults: Evidence from a Cognitive Intervention Program. Dementia and Geriatric Cognitive Disorders, 22, 486-499.

Benedek, M., Jauk, E., Sommer, M., Arendasy, M., \& Neubauer, A. C. (2014). Intelligence, creativity, and cognitive control: The common and differential involvement of executive functions in intelligence and creativity. Intelligence, 46,73-83. org/10.1016/j.intell.2014.05.007

Biswal, B.B., Mennes, M., Zuo, X.N., Gohel, S., Kelly, C., Smith, S.M., Beckmann, C.F., Adelstein, J.S., Buckner, R.L., Colcombe, S. et al. (2010). Toward discovery science of human brain function. Proc Natl Acad Sci USA, 107, 4734-4739.

Bogousslavsky, J., Miklossy, J., Deruaz, J.P., Assal, G., \& Regli, F. (1987). Lingual and fusiform gyri in visual processing: a clinico-pathologic study of superior altitudinal hemianopia. J Neurol Neurosurg Psychiatry, 50, 607-614.

Bollen K., \& Lennox R. (1991). Conventional wisdom on measurement: a structural equation perspective. Psychol Bull. 110, 305-3014.

Bowden, E.M. (1997). The effect of reportable and unreportable hints on anagram solution and the aha! experience. Conscious Cogn, 6, 545-573. doi: 10.1006/ ccog.1997.0325

Brett, M., Anton, J.L., Valabregue, R., \& Poline, J.B. (2002). Region of interest analysis using an SPM toolbox. Presented at the 8th International Conference on Functional Mapping of the Human Brain, Sendai, Japan. Available on CD-ROM in NeuroImage, Vol 16, No 2.

Calhoun, V.D., Adali, T., Pearlson, G.D., \& Pekar, J.J. (2001). A method for making group inferences from functional MRI data using independent component analysis. Hum Brain Map, 14, 140-151.

Cao, W., Cao, X., Hou, C., Li, T., Cheng, Y., Jiang, L., et al. (2016). Effects of Cognitive Training on Resting-State Functional Connectivity of Default Mode, Salience, and Central Executive Networks. Front Aging Neurosci, 8, 70. doi: 10.3389/fnagi.2016.00070. eCollection 2016.

Cassotti, M., Agogué, M., Camarda, A., Houdé, O., \& Borst, G. (2016). Inhibitory control as a core process of creative problem solving and idea generation from childhood to adulthood. In B. Barbot (Ed.), Perspectives on creativity development. New Directions for Child and Adolescent Development, 151, 61-72.

Cavanna, A., \& Trimble, M. (2006). The precuneus: a review of its functional anatomy and behavioural correlates. Brain, 129, 564-583.

Chambon C \& Alescio-Lautier B. (2019) Improved Executive functioning in healthy elderly after a multifactorial cognitive training targeting controlled processes. Journal of Systems and Integrative Neuroscience, $6, \quad 1-9$. doi: 10.15761/JSIN.1000218

Chambon, C., Herrera, C., Romaiguère, P., Paban, V., \& Alescio-Lautier B. (2014). Benefits of a recognition-based memory and attention training program on retrieval in healthy older adults. Psychol Aging, 29, 731-743. doi: 10.1037/a0037477

Chapman, S.B., Aslan, S., Spence, J.S., Hart, J.J., Bartz, E.K., Didehbani, N., et al. (2015). Neural mechanisms of brain 
plasticity with complex cognitive training in healthy seniors. Cereb Cortex, 25. 396405. doi: 10.1093/cercor/bht234.

Chapman, S.B., Spence, J.S., Aslan, S., \& Keeblerdoi, M.W. (2017) Enhancing innovation and underlying neural mechanisms via cognitive training in Healthy older adults. Frontiers in Aging Neuroscience, $\quad 9, \quad 314$. doi:10.3389/fnagi.2017.00314

Clapham, M.M. (1997). Ideational skills training: A key element in creativity training programs. Creativity Research Journal, 10, 33-44.

Cohen, J. (1992). A Power Primer, Psychological Bulletin 112, 155-159.

Cropley, A. (2006). In praise of convergent thinking. Creativity Research Journal, 18, 391-404.

Doi: 10.1080/10400419.2017.1376543.

Dahlin, E., Neely, A. S., Larsson, A., Backman, L., \& Nyberg, L. (2008). Transfer of Learning After Updating Training Mediated by the Striatum. Science, 320(5882), 1510-1512. http://doi.org/10.1126/science.1155466

Deshayes, C., Paban, V., Ferrer, M.H., Alescio-Lautier, B., Chambon, C. (2021). A comprehensive approach to study the resting state brain network related to creativity. Brain Structure and Function, 226(6), 1743-1753. doi :10.1007/s00429021-02286-9

Dresler, M., Wehrle, R., Spoormaker, V., Steiger, A., Holsboer, F., Czisch, M., et al. (2015). Neural correlates of insight in dreaming and psychosis. Sleep Med Rev, 20, 92-99. doi: 10.1016/j.smrv.2014.06.004.

Edwards, J.D., Wadley, V.G., Vance, D.E., Wood K., Roenker, D.L. \& Ball, K.K. (2005). The impact of speed of processing training on cognitive and everyday performance. Aging mental health, 9(3), 62-271.

Fink A., Benedek M., Koschutnig K., Papousek I., Weiss E.M.., Bagga D., Schöpf V. (2018) Modulation of restingstate network connectivity by verbal divergent thinking training. Brain and cognition.

128 , 1-6. doi.org/10.1016/j.bandc.2018.10.008

Fink, A., Benedek, M., Koschutnig, K., Pirker, E., Berger, E., Meister, S., ... Weiss, E. (2015). Training of verbal creativity modulates brain activity in regions associated with language- and memoryrelated demands. Human Brain Mapping, 36 , 4104-4115. https://doi.org/10.1002/hbm.22901

Gates, N., \& Valenzuela M. (2010). Cognitive exercise and its role in cognitive function in older adults. Curr Psychiatry Rep, 12, 20-27. doi: 10.1007/s11920-009-0085-y.

Golden, C. J., 1978. Stroop color and word test. Wood Dale, IL: StoeltingCo.

Goles, T., \& Chin, W.W. (2005). Information systems outsourcing relationship factors: detailed conceptualization and initial evidence. Acm Sigmis Database, 36, 4767.

Goodale, M.A. (2011). Transforming vision into action. Vision Res, 51, 1567-1587.

Guilford, J. P. (1967). The nature of human intelligence. New York, McGraw-Hill.

Haenlein, M., \& Kaplan, A.M. (2004). A beginner's guide to partial least squares analysis. Underst Stat. 3, 283-297

Hagmann, P., Cammoun, L., Gigandet, X., Meuli, R., Honey, C.J., Wedeen, V.J., et al. (2008). Mapping the structural core of human cerebral cortex. PLoS Biol, 6, e159. doi: 10.1371/journal.pbio.0060159.

Hair, J.F., Hult, G.T.M., Ringle, C.M., \& Sarstedt, M. (2014). A Primer on Partial Least Squares Structural Equation Modeling (PLSSEM). Sage, Thousand Oaks

Heaton, R.K., Chelune, G.J., Talley, J.L., Kay, G.G., \& Curtiss, G. (1993). In Wisconsin Card Sort Test Manual: Revised and Expanded. Odessa, FL: Psychological Assessment Resources.

Herrera, C., Chambon, C., Michel B.F., Paban, V., \& Alescio-Lautier, B. (2012). Positive effects of computer-based cognitive training in adults with mild cognitive impairment. Neuropsychologia, 50, 1871-1881. doi: 10.1016/j.neuropsychologia.2012.04.012 
Hussey, E.K., \& Novick, J.M. (2012). The benefits of executive control training and the implications for language processing. Front Psychol, 3, 1-14 doi: 10.3389/fpsyg. 2012.00158

Jolles D.D., van Buchem M.A., Crone E.A., Rombouts S.A. (2013) Functional brain connectivity at rest changes after working memory training. Human brain mapping, 34: 396-406.

Kaplan, C.A., \& Simon, H.A. (1990). In search of insight. Cognitive Psychology, 22, 374-419.

Kim, S., Park, E., Cha, H., Jung,J.C., Jung, T.D., Chang, Y. (2020). Effects of cognitive training in mild cognitive impairment measured by resting state functional imaging. Behavioral Sciences, 10, 175. doi:10.3390/bs10110175

Kleibeuker, S. W., Koolschijn, P. C. M. P., Jolles, D. D., De Dreu, C. K. W., \& Crone, E. A. (2013). The neural coding of creative idea generation across adolescence and early adulthood. Frontiers in Human Neuroscience, 7, 1-12.

Kong. J., Kaptchuk, T.J., Webb J.M., Kong J.T., Sasaki Y., Polich G.R., et al. (2009). Functional neuroanatomical investigation of vision-related acupuncture point specificity-a multisession fMRI study. Human Brain Mapping, 30, 38-46.

Konishi, S., Nakajima, K., Uchida, I., Kikyo, H., Kameyama, M., \& Miyashita, Y. (1999). Common inhibitory mechanism in human inferior prefrontal cortex revealed by event-related functional MRI. Brain, 122, 981-991. 10.1093/brain/122.5.981.

Kozhevnikov M., Kozhevnikov M., Yu C.J., and Blazhenkova O. (2013) Creativity, visualization abilities, and visual cognitive style. British Journal of Educational Psychology, 83, 196-209

Kravitz, D.J., Saleem, K.S., Baker, C.I., Ungerleider, L.G., \& Mishkin, M. (2013). The ventral visual pathway: an expanded neural framework for the processing of object quality. Trends Cogn Sci, 17, 26-49. doi: 10.1016/j.tics.2012.10.011.

Kurtz, A.F., Leucht, S., \& Lautenschlager, N.T. (2011). The clinical significance of cognition-focused interventions for cognitively impaired older adults: a systematic review of randomized controlled trials. Int Psychogeriatr, 23, 1364-1375.

doi: $10.1017 / \mathrm{S} 1041610211001001$

LeBoutillier N. et Marks D.F. (2003), Mental imagery and creativity: a meta-analytic review study. British Journal of Psychology, 94, 29-44.

Levine, B, Stuss, DT, Winocur, G, Binns, MA, Fahy, L, Mandic, et al. (2007). Cognitive rehabilitation in the elderly: Effects on strategic behaviour in relation to goal management. Journal of the International Neuropsychological Society, 13, 143-152.

Likert, R., \& Quasha, W.H. (1941). Revised Minnesota Paper Form Board. New York: Psychological Corporation.

Lin, Z.C., Tao, J., Gao, Y.L., Yin, D.Z., Chen, A.Z., Chen, L.D. (2014). Analysis of central mechanism of cognitive training on cognitive impairment after stroke: resting state functional magnetic resonance imaging study. Journal of International Medical Research, 42, 659-668. Doi: 10.1177/0300060513505809

Luo, J., Li, W., Qiu, J., Wei, D., Liu, Y., \& Zhang, Q. (2013). Neural Basis of Scientific Innovation Induced by Heuristic Prototype. PlosOne, 8, e49231. doi:10.1371/ journal.pone.0049231.

Luo, J., Niki, K., \& Phillips, S. (2004). Neural correlates of the 'Aha! Reaction. Neuroreport, 15, 2013-2017.

Lustig, C., Shah, P., Seidler, R., \& ReuterLorenz, P.A. (2009). Aging, training, and the brain: a review and future directions. Neuropsychol Rev, 19, 504-522. doi:10.1007/s11065-009-9119-9.

Malouin, F., Richards, C.L., Jackson, P.L., Dumas, F., \& Doyon, J. (2003). Brain activations during motor imagery of locomotor-related tasks: a PET study. Hum Brain Mapp, 19, 47-62. doi: 10.1002/hbm.10103

Martindale C. (1990), Creative imagination and neural activity, in K. G. Kunzendorf et A. A. Sheikh (Eds.), The 
psychophysiology of mental imagery. Amityville, NY: Baywood. pp. 89-108.

McCarthy, J. (2018). Do creative thinking and creative problem-solving have a place in counseling curricula? Journal of creativity in mental health, (13) 306 - 317. 10.1080/15401383.2018.1433092

Meinel, M., Wagner, T. F., Baccarella, C. V., \& Voigt, K. (2018). Exploring the effects of creativity training on creative performance and creative self-efficacy: Evidence from a longitudinal study. The Journal of Creative Behavior. https://doi.org/10.1002/jocb.234.

Menon, V., \& Uddin, L.Q. (2010). Saliency, switching, attention and control: a network model of insula function. Brain Struct Funct, 214, 655- $667 . \quad$ doi: 10.1007/s00429-010-0262-0

Metcalfe, J., \& Wiebe, D. (1987). Intuition in insight and noninsight problem solving. Mem. Cogn, 15, 238-246. doi: 10.3758/BF03197722

Miro-Padilla, A., Bueicheku, E., VenturaCampos, N., Flores-Compan, M.J., Parcet, M.A., \& Avila, C. (2019). Long-term brain effects of N-back training: an fMRI study Brain Imaging and Behavior. 13 (4), 11151113. DOI: $10.1007 / \mathrm{s} 11682-018-9925-x$.

Muchinsky, P.M. (2004). Mechanical aptitude and spatial ability testing. In. Thomas J.C., Hersen, M. (Eds), Comprehensive Handbook of Psychological Assessment. Industrial and organizational assessment, Hoboken, NJ: John Wiley and Sons, vol 4: pp 21-33. ISBN 978-0-471-41614-2.

Murdock, M.C., Isaksen, S.G., \& Lauer, K.J. (1993). Creativity training and the stability and internal consistency of the Kirton adaption-innovation inventory. Psychological Reports, 72,1123-1130.

Ness RB. (2012). Innovation Generation: How to Produce Creative and Useful Scientific Ideas. New York, NY: Oxford.

Ness, R.B. (2015). Promoting innovative thinking. Am J Public Health, 105, 114118. doi: 10.2105/AJPH.2014.302365.

Puccio G.J., Burnett C., Acar S., Yudess J.A., Holinger M., Cabra J.F. (2020) Creative Problem Solving in Small Groups: The
Effects of Creativity Training on Idea Generation, Solution Creativity, and Leadership Effectiveness. Journal of Creative Behavior, 54, 453-471. doi.org/10.1002/jocb.381

Qiu, J., Li, H., Jou, J., Liu, J., Luo, Y., Feng, T., et al. (2010). Neural correlates of « Aha " experiences: Evidence from an fMRI study of insight problem solving. Cortex, 46,397-403.

doi:10.1016/j.cortex.2009.06.006

Radel R., Davranche K., Fournier M., Dietrich A. (2015) The role of (dis)inhibition in creativity: Decreased inhibition improves idea generation. Cognition, 134, 110-120. doi.org/10.1016/j.cognition.2014.09.001

Raz, A., \& Buhle, J. (2006). Typologies of attentional networks. Nature Reviews Neuroscience, 7, 367-379.

Riou J, Guyon H, \& Falissard B. (2016). An introduction to the partial least squares approach to structural equation modelling: a method for exploratory psychiatric research. Int J Methods Psychiatr Res, 25, 220-231. doi: 10.1002/mpr.1497.

Roenker, D.L., Cissell, C.B., Ball, K.K., Wadley, V.G., \& Edwards J.D. (2003). Speed-of-processing and driving simulator training result in improved driving performance. Human Factors, 45(2), 218233.

Rubinov, M., \& Sporns, O. (2010). Complex network measures of brain connectivity: uses and interpretations. Neuroimage, 52, 1059-1069. doi: 10.1016/j.neuroimage.2009.10.003.

Schaie, K.W. (1994). The course of adult intellectual development. American Psychologist, 49, 304-313.

Schaie, K.W. (1996). Intellectual development in adulthood: The Seattle Longitudinal Study. New York, Cambridge University Press.

Schaie, K.W. (2004). Developmental influences on cognitive development: The Seattle Longitudinal. Study. New York, Oxford University Press.

Schooler, J.X., Ohlsson, S., \& Brooks, K. (1993). Thoughts beyond words: When language overshadows insight. $\mathrm{J}$ Exp 
Psychol, 122, 166-183. Doi: 10.1037/0096-3445.122.2.166.

Scott G., Leritz L.E. \& Mumford M.D. (2014) Types of creativity training: Approaches and their effectiveness. Journal of creative behavior, 38, 149-179.

Shen, W., Luo, J., Liu, C., \& Yuan, Y. (2013). New advances in the neural correlates of insight: A decade in review of the insightful brain. Psychol Cog Sciences, 58, 1497-1511. doi: 10.1007/s11434-012$5565-5$

Shen, W., Yuan, Y., Liu, C., Zhang, X., Luo, J., \& Gong, Z. (2016). Is creative insight task-specific? A coordinate-based metaanalysis of neuroimaging studies on insightful problem solving. Int $\mathbf{J}$ Psychophysiol, 110, 81-90. doi: 10.1016/j.ijpsycho.2016.10.001

Small, G.W., Silverman D.H., Siddarth P., Ercoli L.M., Miller K.J., Lavretsky H. (2006). Effects of a 14-day healthy longevity lifestyle program on cognition and brain function. Am $\mathrm{J}$ Geriatr Psychiatry. 14(6), 538-45.

Sporns, O., \& Honey., C.J. (2013). Topographic dynamics in the resting brain. Neuron, 78, 955-956. doi: 10.1016/j.neuron.2013.05.037.

Squire L.R. (2014) Memory systems of the brain: A brief history and current perspective. Neurobiology of Learning and Memory, 82, 171-177. doi:10.1016/j.nlm.2004.06.005

Stavridou A., \& Furnham A. (1996) The relationship between psychoticism, traitcreativity and the attentional mechanism of cognitive inhibition. Perrson. Indvid. Diff, 21, 143-153.

Stigsdotter, A. \& Bäckman, L. (1989). Multifactorial memory training with older adults : How to foster maintenance of improved performance. Gerontology, 35, 260- 267.

Stigsdotter-Neely, A.S., \& Bäckman, L. (1993). Maintenance of gains following multifactorial and unifactorial memory training in late adulthood, Educational Gerontology, 19, 105- 111.
Stigsdotter-Neely, A.S., \& Bäckman L. (1995). Effects of multifactorial memory training in old age: Generalizability across tasks and individuals. Journal of Gerontology: Psychological Sciences, 50, 134-140.

Storm, B.C., \& Angello, G. (2010). Overcoming fixation: Creative problem solving and retrieval-induced forgetting. Psychological Science, 21, 1263-1265.

Styliadis, C., Kartsidis, P., Paraskevopoulos, E., Ioannides A.A., Bamidis, P.D. (2015). Neuroplastic effets of combined Computerized physical and cognitive training in elderly individuals at risk for dementia: An eLORETA controlled study on resting states. Hindawi Publishing Corporation, Neural Plasticity. doi.org/10.1155/2015/172192.

Takeuchi H., Taki Y., Sassa Y., Hashizume H., Sekiguchi A., Fukushima A., R Kawashima. (2011) Working memory training using mental calculation impacts regional gray matter of the frontal and parietal regions? PloS One, 6, e23175. doi:10.1371/journal.pone.0023175.

Tik M., Sladky R., Luft C.D.B., Willinger D. Hoffmann A., Banissy M.J, et al. (2018). Ultra-high-field fMRI insights on insight: Neural correlates of the Aha!moment. Human Brain Mapping. 39, 32413252. DOI: $10.1002 / \mathrm{hbm} .24073$

Utevsky, A.V., Smith, D.V., \& Huettel, S.A. (2014). Precuneus is a functional core of the default-mode network. J Neurosci, 34, 932-940. doi: 10.1523/JNEUROSCI.422713.2014.

Valenzuela, M.J., Jones, M., Wen, W., Rae C., Graham, S., Shnier, R., \& Sachdev, P. (2003). Memory training alters hippocampal neurochemistry in healthy elderly. Neuroreport, 14(10), 1333-1337.

Valenzuela, M.J., Sachdev, P., Wen, W., Chen, X., \& Brodaty, H. (2008). Lifespan mental activity predicts diminished rate of hippocampal atrophy. PLoS One., 3(7), e2598.

Valenzuela, M.J., \& Sachdev P. (2009). Can cognitive exercise prevent the onset of dementia? Systematic review of 
randomized clinical trials with longitudinal follow-up. Am J Geriatr Psychiatry, 17, 179-187.

Vally Z., Salloum L., AlQedra D., El Shazly S., Albloshi M., Alsheraifi S., \& Alkaabi A. (2019) Examining the effects of creativity training on creative production, creative self-efficacy, and neuro-executive functioning. Thinking skills and creativity, 31 , $70-78$ doi.org/10.1016/j.tsc.2018.11.003

Watts, D.J., \& Strogatz, S.H. (1998). Collective dynamics of "small-world" networks. Nature, 393, 440-442.

Webb, M.E., Little, D.R., \& Cropper, S.J. (2016). Insight Is Not in the Problem: Investigating Insight in Problem Solving across Task Types. 7, 1424. Doi: 10.3389/fpsyg.2016.01424.

Weisberg, R.W. (2014). Toward an integrated theory of insight in problem solving. Think. Reason, 21, 5-39. doi: 10.1080/13546783.2014.886625

Westerberg, H., Jacobaeus, H., Hirvikoski, T., Clevberger, P., Östensson, M. L., Bartfai,A., et al. (2007). Computerized working memory training after stroke - A pilot study. Brain Injury, 21, 21-29. doi: 10.1080/02699050601148726.

Whitfield-Gabrieli, S., \& Nieto-Castanon, A. (2012). Conn: a functional connectivity toolbox for correlated and anticorrelated brain networks. Brain Connect, 2, 125-141. doi: 10.1089/brain.2012.0073.

Wimmer, L. (2016). Problem solving as a sufficient condition of the creative process: A case for closer cooperation of creativity research and problem solving research. Frontiers in Psychologie, 7, 1-4. doi: 10.3389/fpsyg.2016.00488.

Winocur, G., Craik, F.I.M., Levine, B., Robertson, I.H., Binns, M.A., Alexander, M., et al. (2007). Cognitive rehabilitation in the elderly: effects on strategic behavior in relation to goal management. Journal of the International Neuropsychological Society, 13(1), 143-52.

Wolinsky, F.D., Unverzagt, F.W., Smith, D.M., Jones, R., Wright, E., \& Tennstedt S.L. (2006). The effects of the ACTIVE cognitive training interventions on clinically relevant declines in healthrelated quality of life. The Journals of Gerontology: Social Sciences, 61B, 281287.

Yesavage, J.A., \& Rose TL. (1983). Concentration and mnemonic training in elderly subjects with memory complaints: A study of combined therapy and order effects. Psychiatry Research, 9, 157-167.

Yesavage, J.A, Sheikh, J.I., Friedman, L., \& Tanke, E. (1990). Learning mnemonics: Roles of aging and subtle cognitive impairment. Psychology and Aging, 5, 133- 137.

Zhang, M., Tian, F., Wu, X., Liao, S., \& Qiu, J. (2011). Neural correlates of "Aha!" effects in solving Chinese verbal problems: An event related-potential study. Brain Res Bull, 84, 210-214. doi 10.1016/j.brainresbull.2011.01. 


\section{Supplemental material}

\section{Experiment 1: Attention task}

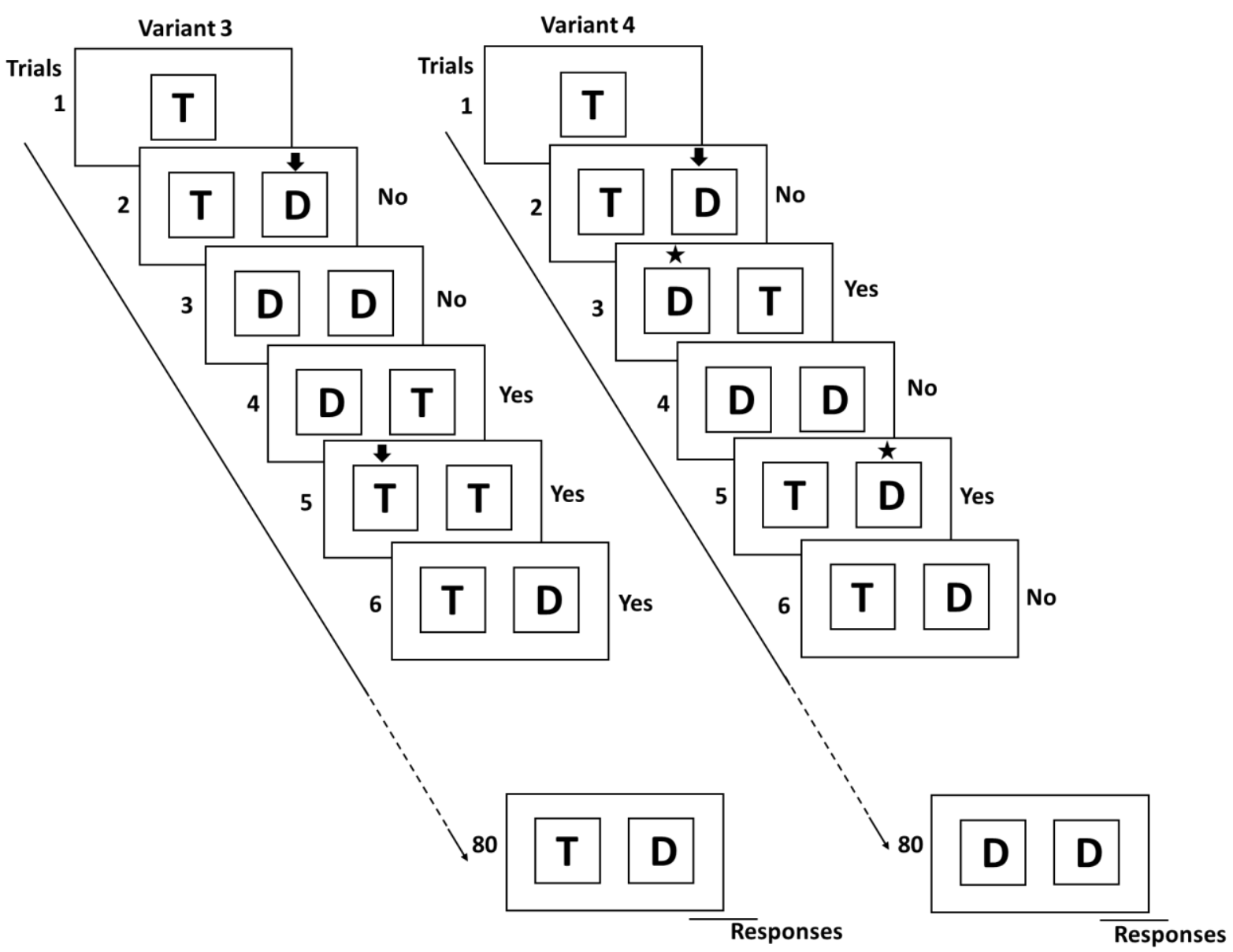

Attention task: $\mathrm{T}=$ Target; $\mathrm{D}=$ Distractor (or lure)

\section{Experiment 2: problem solving training}

Subjects were trained on approximately 120 problems selected from a library of 400 problems. These problems were listed according to their predominant modality: semantic, mathematical, visual, visuospatial, etc., and according to their difficulty. It should be noted that the classification of certain problems as easy or difficult was questioned because it depended on the subject. This was especially the case for problems that were solved in the insight mode by 
the subjects compared to subjects who had difficulties expressing this mode of resolution, particularly at the beginning of the training. The choice of problems and their level was therefore made for each subject according to their abilities and difficulties. This procedure was adjusted throughout the training.

\section{- simple closed-ended problems}

-In math, how many times can you subtract 5 from 25 ?

Answer: 1 time because after the first step you subtract 5 to 20, etc.

-How many drops of water can you put in an empty glass?

Answer: 1 only because after it is not empty anymore

-Two gardeners rake a park, one of them makes 3 piles and the other makes 7.

When they put the results of their work together, how many piles will they have in front of them?

Answer: One pile

-In total, how many fully drawn squares can you count?



Answer: 11
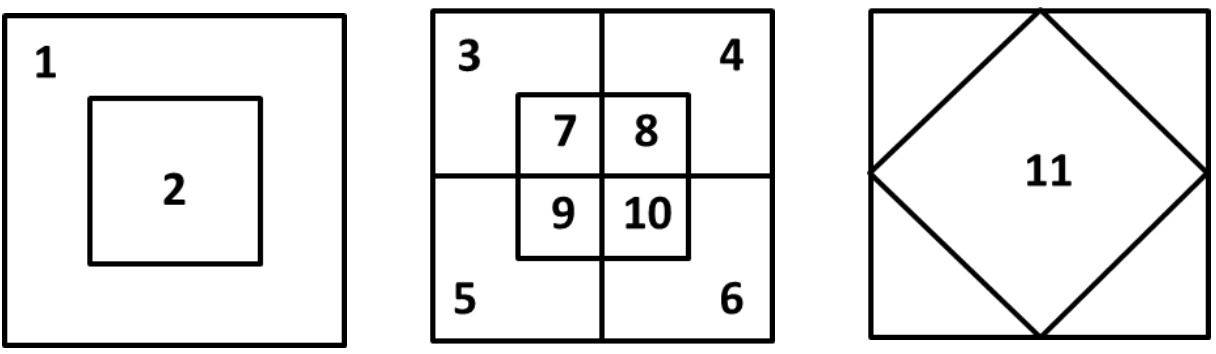
-In one line, without ever lifting the pencil and without going over the same place twice, try to reproduce this drawing.
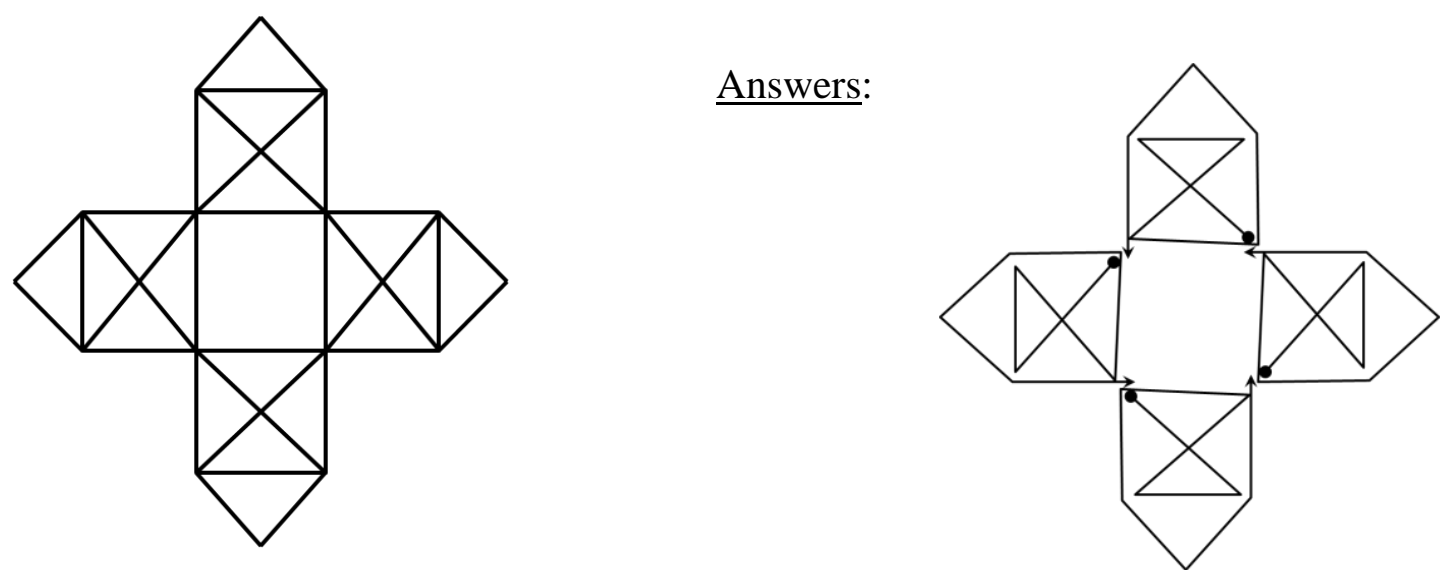

-Find a way through this maze, knowing that:

You cannot pass through the same square more than once,

The sum of the numbers of the chosen squares must be equal to 13 .

\begin{tabular}{|l|l|l|l|}
\hline 3 & 1 & 5 & 1 \\
\hline 2 & 0 & 1 & 4 \\
\hline 2 & 4 & 2 & 4 \\
\hline 3 & 3 & 1 & 0 \\
\hline
\end{tabular}

There are other paths, try to find them.

Answers:

\begin{tabular}{|l|l|l|l|}
\hline 3 & 1 & 5 & 1 \\
\hline 2 & 0 & 1 & 4 \\
\hline 2 & 4 & 2 & 4 \\
\hline 3 & 3 & 1 & 0 \\
\hline
\end{tabular}

\begin{tabular}{|l|l|l|l|}
\hline 3 & 1 & 5 & 1 \\
\hline 2 & 0 & 1 & 4 \\
\hline 2 & 4 & 2 & 4 \\
\hline 3 & 3 & 1 & 0 \\
\hline
\end{tabular}

\begin{tabular}{|l|l|l|l|}
\hline 3 & 1 & 5 & 1 \\
\hline 2 & 0 & 1 & 4 \\
\hline 2 & 4 & 2 & 4 \\
\hline 3 & 3 & 1 & 0 \\
\hline & &
\end{tabular}



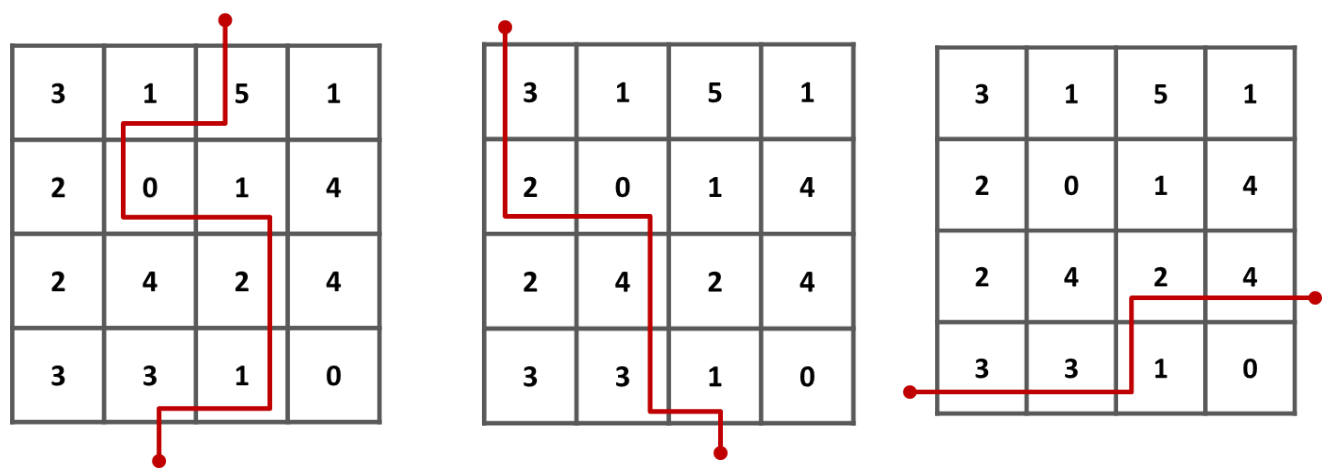

-How do you arrange these ten pieces so that there are five rows of four pieces each?
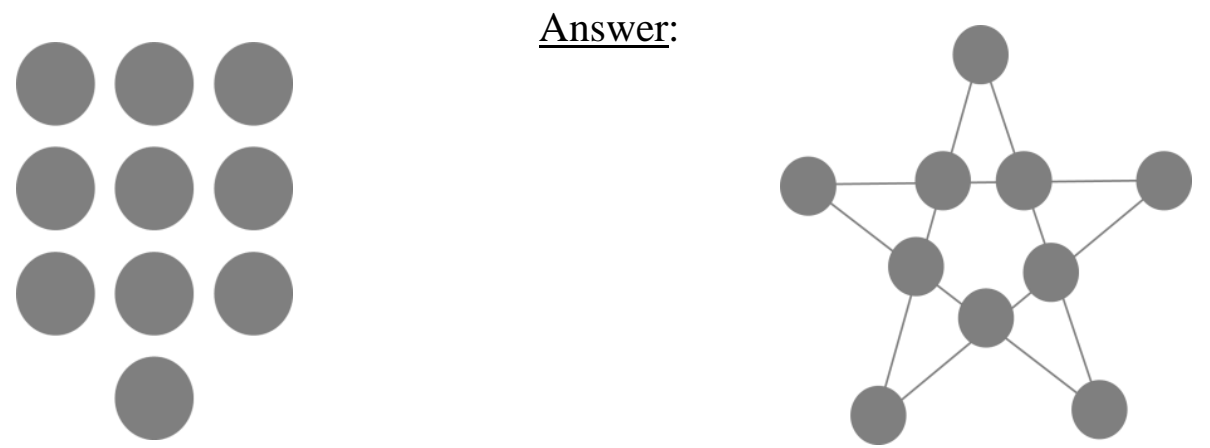

-A tourist walks in the middle of the sand dunes. He was with a group of travelers, but he got lost. Desperate, he walks northwards hoping to find the others. His only luggage is a digital camera and a pair of binoculars. He is exhausted and thirsty. At the top of a sandy mountain, a miracle happens. He sees an oasis. A vast watering place, palm trees and even animals. Taking hope again, he goes down the slope in the direction of what he hopes is not a mirage. A few hundred meters from the source, he crosses a caravan of travelers. It counts 3 camels and 2 dogs. The camels each carry 1 man and 2 cages containing 3 birds each. One of the men carries a wounded dog in his arms. The dogs are dirty and seem to be covered with fleas.

The tourist then asks himself the question: how many living creatures are going to the watering hole?

Answer: Only one person still alive goes to the watering hole...

- Two cities 1,000 km distant are connected by a double track railroad. At one point, two trains traveling at $100 \mathrm{~km} / \mathrm{h}$ leave each city and head for the other.

A fly traveling at $150 \mathrm{~km} / \mathrm{h}$ begins a continuous round trip between the two trains.

How far will the fly have traveled by the time the two trains pass each other? 
Answer: The fly will have traveled $750 \mathrm{~km}$.

Explanation:

First, we look at the trains:

Since the trains are traveling at $100 \mathrm{~km} / \mathrm{h}$ and the distance between them is $1000 \mathrm{~km}$, they will meet halfway, so after 5 hours.

We are then interested in the fly:

Since the fly flies at $150 \mathrm{~km} / \mathrm{h}$, it will have flown for 5 hours, so it will have traveled $5 \mathrm{x} 150$ $=750 \mathrm{~km}$.

- You must give 4 Liters of water.

For this, you have only 2 jars: the first one of 5 Liters and the second of 3 Liters.

How are you going to do it?

\section{Solution 1:}

Fill the $5 \mathrm{~L}$ jar and empty it into the $3 \mathrm{~L}$ jar.

Empty the $3 \mathrm{~L}$ jar and transfer the remaining $2 \mathrm{~L}$ into the $5 \mathrm{~L}$ jar.

Fill the $5 \mathrm{~L}$ jar and then transfer the liter needed to finish filling the $3 \mathrm{~L}$ jar.
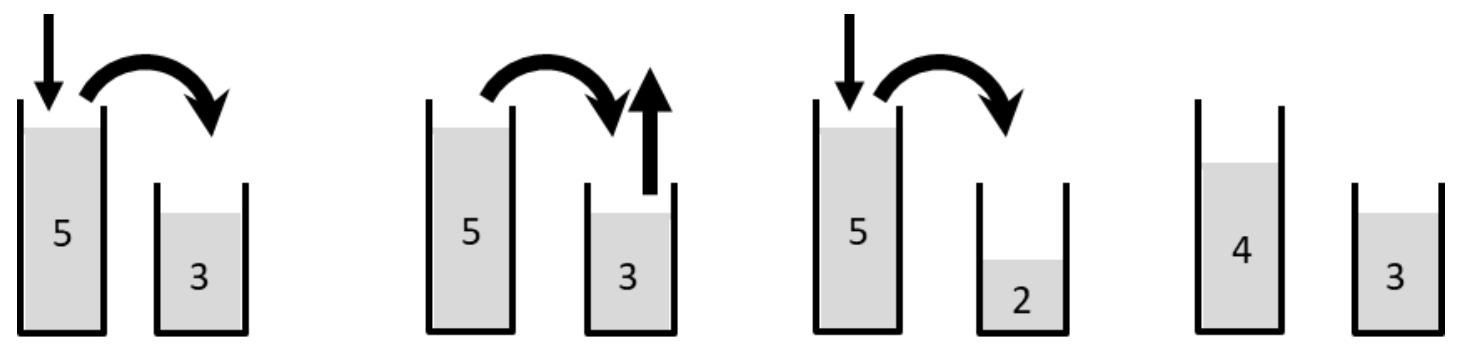

\section{Solution 2:}

Fill the $3 \mathrm{~L}$ jar and empty it into the $5 \mathrm{~L}$ jar

Fill the $3 \mathrm{~L}$ jar and empty it into the $5 \mathrm{~L}$ jar until it is full.

Empty the $5 \mathrm{~L}$ jar and refill it with the remaining $1 \mathrm{~L}$ from the $3 \mathrm{~L}$ jar.

Fill the $3 \mathrm{~L}$ container and empty it into the $5 \mathrm{~L}$ container.
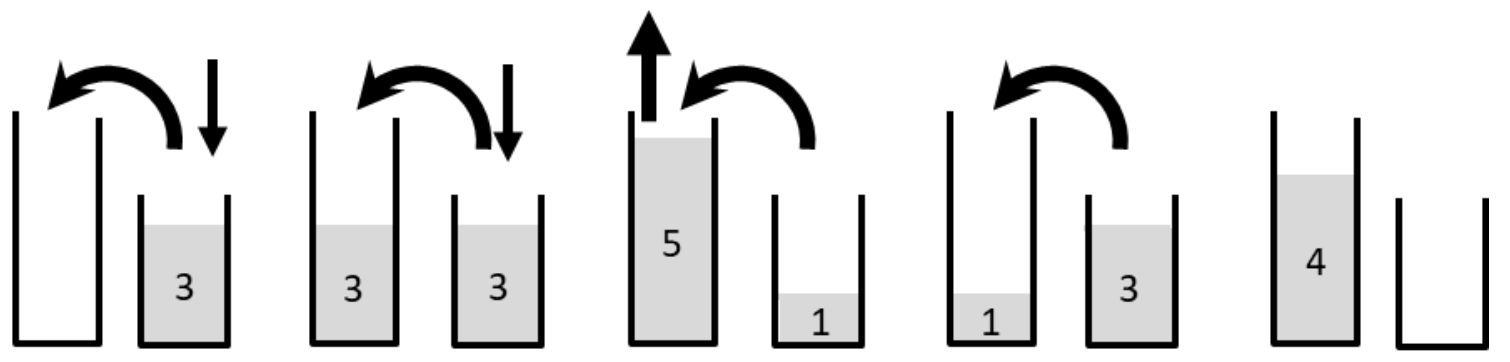
-A room measures 12 by 9 meters; in its middle, there is a wall 8 meters long and 1 meter thick. This room therefore has a living area of 100 square meters. It is represented on the figure below:

We have a 10 x 10 meter piece of carpet:
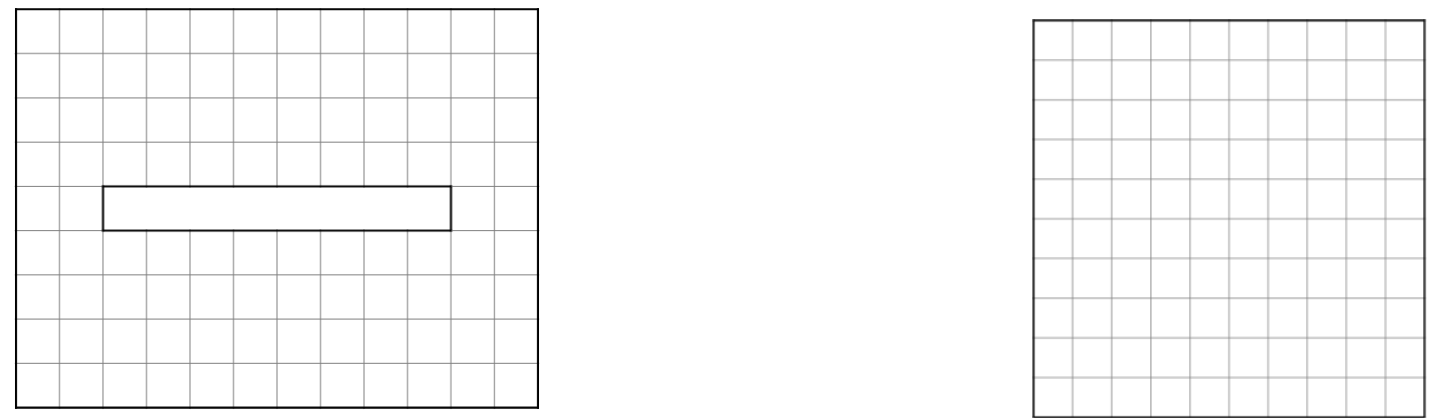

How can the room be covered with the carpet by cutting it into 2 equal and overlapping pieces?

\section{Answer:}

Here is the carpet
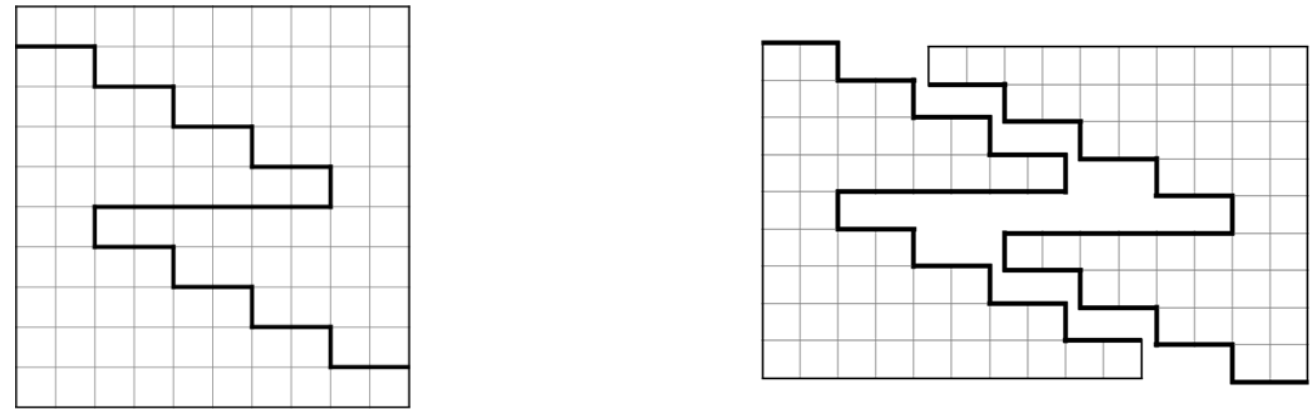

And here is the room thus covered

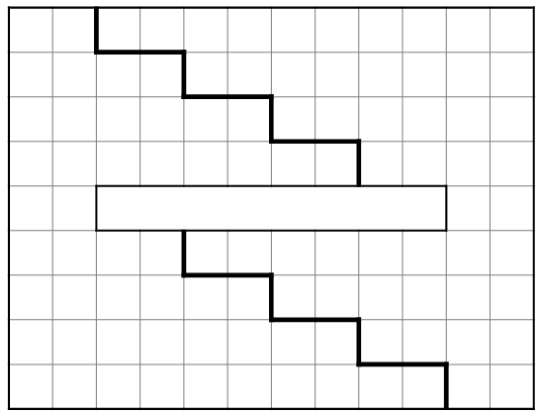

